\title{
Disorders of consciousness after acquired brain injury: the state of the science
}

\author{
Joseph T. Giacino, Joseph J. Fins, Steven Laureys and Nicholas D. Schiff
}

\begin{abstract}
The concept of consciousness continues to defy definition and elude the grasp of philosophical and scientific efforts to formulate a testable construct that maps to human experience. Severe acquired brain injury results in the dissolution of consciousness, providing a natural model from which key insights about consciousness may be drawn. In the clinical setting, neurologists and neurorehabilitation specialists are called on to discern the level of consciousness in patients who are unable to communicate through word or gesture, and to project outcomes and recommend approaches to treatment. Standards of care are not available to guide clinical decision-making for this population, often leading to inconsistent, inaccurate and inappropriate care. In this Review, we describe the state of the science with regard to clinical management of patients with prolonged disorders of consciousness. We review consciousness-altering pathophysiological mechanisms, specific clinical syndromes, and novel diagnostic and prognostic applications of advanced neuroimaging and electrophysiological procedures. We conclude with a provocative discussion of bioethical and medicolegal issues that are unique to this population and have a profound impact on care, as well as raising questions of broad societal interest.
\end{abstract}

Giacino, J. T. et al. Nat. Rev. Neurol. advance online publication 28 January 2014; doi:10.1038/nrneurol.2013.279

\section{Introduction}

Disorders of consciousness (DOC) present both clinical challenges of diagnosis and treatment and unique opportunities for fundamental scientific discoveries about the nature of human consciousness. ${ }^{1}$ Moreover, advances in the assessment and rehabilitation of patients with the severe brain injuries that produce DOC have a tremendous impact on medical practice and ethics. ${ }^{2-4}$

In this Review, we provide an overview of recent advances in the neurobiology, diagnosis and treatment of DOC, including the use of novel neuroimaging and electrophysiological assessments. We also discuss the medicolegal and ethical issues surrounding these advances that will influence the medical care of patients with DOC.

\section{What is consciousness?}

Many definitions of consciousness have been proposed, none of which completely avoids an element of tautology or self-reference. However, a definition closely following that of William James $(1894)^{5}$ is useful for framing DOC across a continuum. ${ }^{6}$ According to James, "at its least, normal human consciousness consists of a serially time-ordered, organized, restricted and reflective awareness of self and the environment. Moreover, it is an experience of graded complexity and quantity." Missing from this definition, however, is the intimate linkage between arousal level, which indexes both unconscious and conscious brain states (including stages of sleep from unconscious stage 3 slow-wave sleep to the conscious

Competing interests

The authors declare no competing interests. imagery of rapid eye movement [REM] sleep, levels of responsiveness across the range of DOC, and variations in the effects of anaesthetics from coma to light sedation), and the core neuropsychological components of normal, awake, conscious brain function that provide the contents of consciousness (a range of specific functional types of attention, intention, memory, awareness and mood-emotion). Broadly speaking, DOC affect both arousal level and the contents of consciousness.

\section{Disorders of consciousness}

DOC can result from focal brain injuries that induce widespread functional changes, or from more-global injuries. DOC are categorized largely on the basis of observable behavioural features and their inferred relationship to level of consciousness-diagnostic taxonomies based on pathophysiological mechanisms have not yet been developed. DOC exist on a continuum, and patients may or may not transition sequentially through each state of consciousness.

Accurate differential diagnosis is essential to the clinical management of patients with DOC. Diagnosis drives the approach to treatment, and is strongly associated with functional outcome. ${ }^{7.8}$ Augmentative communication training, for example, should be deferred until the patient transitions to MCS and demonstrates evidence of language comprehension. The clinical examination should be designed to identify the key distinguishing features (Table 1), so that the prognosis can be established and appropriate therapeutic interventions initiated as early as possible. 


\section{Key points}

- Disorders of consciousness (DOC) arise from direct perturbations of neural systems that regulate arousal and awareness, and indirectly from disruptions in the connections between these systems

- Distinct clinical syndromes have been identified, but behavioural features often fluctuate and cross diagnostic borders within individual patients, probably reflecting aberrant dynamic changes in corticothalamic neuronal activity

- Novel applications of functional neuroimaging and electrophysiological techniques have been employed to detect covert signs of conscious awareness, improve outcome prediction, and establish brain-computer interfaces to augment communication ability

- Recent empirical evidence suggests that treatment interventions aimed at neuromodulation can accelerate recovery and enhance outcome during both the acute and chronic phases

- A paradigm shift should change the pervasive nihilism that continues to complicate patient management, family adjustment, medicolegal issues and healthcare policy in relation to DOC

\section{Coma}

Coma is usually the result of severe, diffuse, bihemispheric lesions of the cortex or underlying white matter, bilateral thalamic damage, or focal lesions of the paramedian tegmentum. The defining clinical feature of coma is the complete loss of spontaneous or stimulus-induced arousal. No sleep-wake cycles are evident on EEG, the eyes remain continuously closed, and there is no speech or purposeful motor activity, following commands or sensory stimulation. ${ }^{9}$ Coma is a self-limiting state that typically resolves within 2 weeks and transitions into either a vegetative state (VS) or a minimally conscious state (MCS).

\section{Vegetative state}

VS is a condition of wakeful unconsciousness. The diagnosis of VS is made when spontaneous eye-opening reemerges (signalling recovery of the reticular activating system), despite the continued absence of any discernible evidence of language comprehension, verbal or gestural communication, or reproducible purposeful behavioural responses to visual, auditory, tactile or noxious stimuli. ${ }^{10}$ The term persistent VS (PVS) is applied when VS persists for at least 1 month. PVS is considered to be permanent 3 months after non-traumatic brain injury, or after 12 months following traumatic injury. Because recovery of consciousness commonly occurs 3-12 months postinjury, ${ }^{11,12}$ the Aspen Neurobehavioural Conference Workgroup suggested that the term 'PVS' should be abandoned, recommending instead that the term 'VS' should be used in association with the aetiology of the injury (traumatic or non-traumatic) and the length of time since onset, as these factors have been shown to influence outcome., ${ }^{73}$

\section{Minimally conscious state}

MCS is a condition of severely altered consciousness characterized by minimal but definite behavioural evidence of self or environmental awareness. ${ }^{14}$ MCS usually exists as a transitional state reflecting improvement in consciousness following coma or VS, or progressive decline as in neurodegenerative disease. The typical lesion profile consists of grade II or III diffuse axonal injury with multifocal cortical contusions, sometimes accompanied by thalamic involvement. In comparison to patients diagnosed with VS, thalamic lesions are notably less prevalent in MCS. ${ }^{15}$ The relative preservation of long-range corticothalamic connections might explain why patients in MCS retain the capacity for cognitive processing.

Diagnosis of MCS is based on clearly discernible and reproducible evidence of simple command-following, intelligible speech or recognizable "yes-no" responses (verbal or gestural), and/or nonreflexive behaviours that are selectively triggered by specific environmental stimuli. Examples of the latter behaviours include sustained visual pursuit of an object or person, smiling or crying following exposure to emotional stimuli (for example, family photographs) but not neutral stimuli (for example, photographs of objects), vocalizations or gestures that occur in direct response to verbal or gestural prompts, reaching toward objects placed within the field of view, and manual manipulation of objects placed in the hand. The hallmark feature of MCS is response inconsistency; that is, the examiner may elicit clear evidence of volitional behaviour on one examination, but fail to do so during a subsequent examination conducted hours or even minutes later. Serial assessment is frequently required to capture sufficient evidence of MCS, because the behaviour of interest might occur infrequently, or could be ambiguous or masked by concurrent complications.

Akinetic mutism (AM) is a subtype of MCS, in which the failure to follow commands, speak and engage in other goal-directed behaviour is due to severely diminished drive, rather than decreased arousal or direct damage to neural systems responsible for mediating these behaviours. In AM, speech, movement, thought and emotional expression are uniformly reduced ${ }^{16,17}$ but, unlike in MCS, these responses may be facilitated following exposure to high-intensity sensory or personally salient stimuli. This phenomenon is exemplified in the so-called 'telephone effect', originally described by C. Miller Fisher. ${ }^{18}$ Some patients with AM, who are otherwise mute and behaviourally non-responsive when verbally prompted, will speak fluently and conversationally over the telephone. Fisher suggested that the discriminative sensory cues associated with this behaviour (for example, the telephone itself, or the ringing sound), coupled with the over-learned act of speaking on the telephone, might produce a temporary reversal of the severe decrease in drive that arises from marked downregulation of the 'mesencephalofrontal activating system'-an earlier iteration of the mesocircuit model described below.

DOC must be differentiated from locked-in syndrome (LIS), a rare condition caused by damage to corticospinal and corticobulbar pathways that spares consciousness and cognition but leaves the patient aphonic and quadriplegic. ${ }^{9}$ Vertical eye movements and blinking are typically spared, allowing eventual breakthrough of gaze-based communication and expression of high-level cognition. ${ }^{19-21}$ The efferent loss of speech and movement in LIS is often misattributed to disturbance in consciousness, leading to frequent misdiagnosis. ${ }^{22}$ Further complicating matters, in some cases LIS presents as VS or MCS in the acute stage and subsequently evolves into the classic LIS syndrome. ${ }^{23,24}$ 
Table 1 | Characteristic clinical features of disorders of consciousness

\begin{tabular}{|c|c|c|c|c|c|c|}
\hline Disorder & Arousal and attention & Cognition & $\begin{array}{l}\text { Receptive } \\
\text { language }\end{array}$ & Expressive language & Visuoperception & Motor function \\
\hline Coma & No sleep-wake cycles* & None & None & None & None & Primitive reflexes only \\
\hline $\begin{array}{l}\text { Minimally } \\
\text { conscious } \\
\text { state }\end{array}$ & $\begin{array}{l}\text { Intermittent periods } \\
\text { of wakefulness }\end{array}$ & $\begin{array}{l}\text { Inconsistent but } \\
\text { clear-cut behavioural } \\
\text { signs of self-awareness } \\
\text { or environmental } \\
\text { awareness }\end{array}$ & $\begin{array}{l}\text { Inconsistent } \\
\text { one-step } \\
\text { command- } \\
\text { following* }\end{array}$ & $\begin{array}{l}\text { Aspontaneous and limited } \\
\text { to single words or short } \\
\text { phrases* }\end{array}$ & $\begin{array}{l}\text { Visual pursuit* } \\
\text { Object } \\
\text { recognition* }\end{array}$ & $\begin{array}{l}\text { Localization to } \\
\text { noxious stimuli* } \\
\text { Object manipulation* } \\
\text { Automatic movement } \\
\text { sequences* }\end{array}$ \\
\hline $\begin{array}{l}\text { Post-traumatic } \\
\text { confusional } \\
\text { state }\end{array}$ & $\begin{array}{l}\text { Extended periods } \\
\text { of wakefulness }\end{array}$ & $\begin{array}{l}\text { Confused and } \\
\text { disoriented* }\end{array}$ & $\begin{array}{l}\text { Consistent one- } \\
\text { step command- } \\
\text { following }\end{array}$ & $\begin{array}{l}\text { Sentence-level speech, often } \\
\text { confused, perseverative } \\
\text { Reliable yes-no responses* }\end{array}$ & $\begin{array}{l}\text { Object } \\
\text { recognition }\end{array}$ & $\begin{array}{l}\text { Functional use of } \\
\text { common objects* }\end{array}$ \\
\hline $\begin{array}{l}\text { Locked-in } \\
\text { syndrome }\end{array}$ & $\begin{array}{l}\text { Normal sleep-wake } \\
\text { cycles }\end{array}$ & Normal to near-normal & Normal & Aphonic & Normal & Tetraplegia \\
\hline
\end{tabular}

\section{Acute confusional state}

Emergence from MCS is signalled by the re-emergence of a functional communication system or restoration of the ability to use objects in a functional manner. Operationally, recovery of communication is demonstrated by reliable yes-no responses to questions concerning personal orientation (for example, "is your name Bill/Jim?”) or situational orientation (for example, "are you sitting in a chair/bathtub?"). Functional object use is assessed by testing instrumental praxis (for example, "show me how to use a cup/hairbrush").

Patients newly emerged from MCS remain acutely confused and disoriented, and may be prone to episodes of agitation - a condition termed acute confusional state (ACS). The full constellation of symptoms associated with ACS includes temporal and spatial disorientation, distractibility, anterograde amnesia, impaired judgement, perceptual disturbance, restlessness, sleep disorder, and emotional lability. Formal criteria have recently been proposed to establish the onset and resolution of the post-traumatic confusional state, ${ }^{25}$ and specific symptoms of ACS have been linked to functional outcome. ${ }^{26}$ Coexisting peripheral and cortical sensory impairments (for example, deafness, blindness) and cognitive dysfunction (for example, apraxia, agnosia) and language disturbance (for example, aphasia) should be ruled out as contributing or causative factors in patients who fail to meet the criteria for reliable communication ability or functional object use, although this is often difficult to accomplish on bedside examination.

\section{Neurobiology of consciousness}

\section{Creating and maintaining the conscious state}

Much recent effort has focused on the neurobiological underpinnings of the conscious state, beginning with experimental studies isolating the roles of several core brainstem, basal forebrain and hypothalamic systems in supporting variations in neuronal firing patterns across the entire corticothalamic system in relation to different levels of arousal. ${ }^{27-29}$ Most investigators agree that the awake conscious state is fundamentally identified with highly energy-demanding activity within the corticothalamic system. ${ }^{29-32}$ These energy demands derive strongly from complex, high-frequency neuronal firing patterns associated with depolarization of cortical, thalamic and striatal membrane potentials. ${ }^{29,33,34}$ Large reductions in arousal level in normal individuals involve broad hyperpolarization of these neurons via withdrawal of excitatory neuromodulatory influences from orexinergic, cholinergic, noradrenergic and other brainstem, basal forebrain and hypothalamic systems. ${ }^{27-29}$ Such hyperpolarization of cortical and thalamic neurons, as progressively occurs across deeper stages of sleep (or with broad inhibitory effects of anaesthesia), markedly shifts the firing patterns of these neuronal populations, and influences the overall pattern of corticothalamic dynamics toward more-synchronous and dynamically stereotyped waves of activity compared with the more spatiotemporally differentiated patterns associated with the wakeful conscious state. ${ }^{35}$

The mechanistic link between consciousness and the more depolarized, activated and spatiotemporally complex activated state has not been formulated. Nonetheless, several key requirements have been proposed, particularly with respect to the types of brain activity that correlate with conscious brain states, ${ }^{36}$ the timescales of specific neurophysiological processes that are consistent with psychophysiological measurements of awareness, and the role of global availability of information across the brain. ${ }^{31}$ Experimental studies that focus on contrasts between nonconscious and conscious processing of information in normal individuals demonstrate that conscious brain activity is typically associated with widely distributed brain regions within the prefrontal and parietal cortex, the sensory areas of which show synchronous activity and late amplification of activity. ${ }^{31}$ Such processes are posited to be necessary for an abstract distributed dynamic activity, known as the global workspace, to have access to sensory or internal cognitive representations and maintain activation over hundreds of milliseconds. 


\section{REVIEWS}

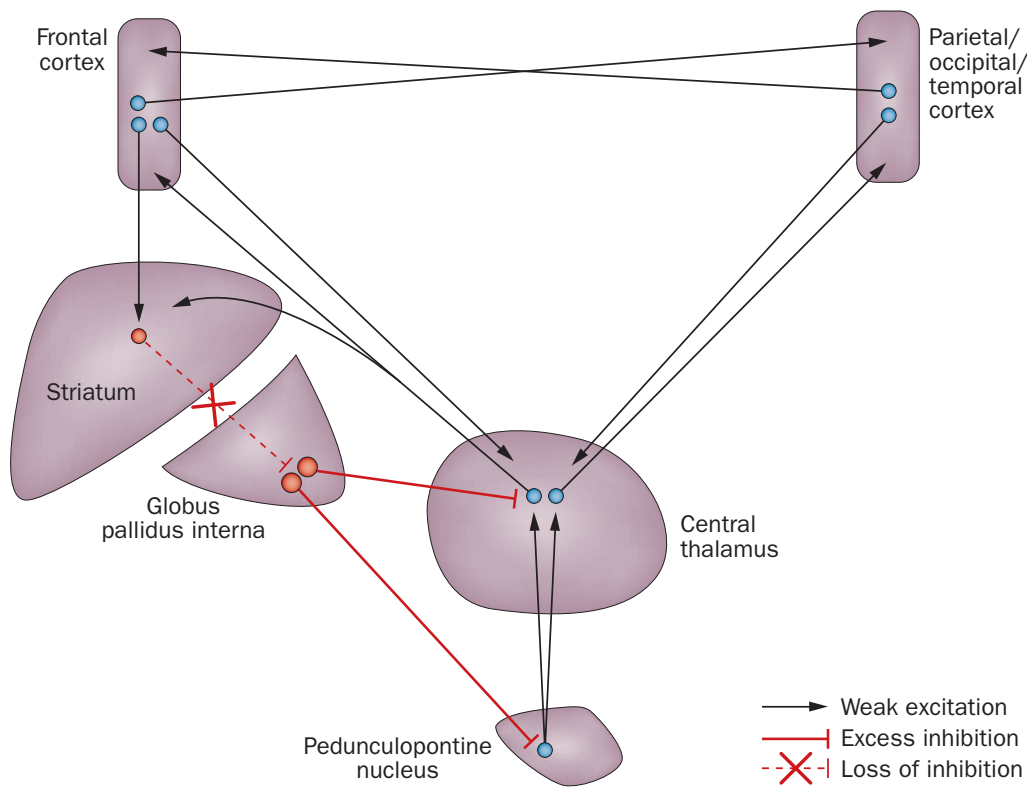

Figure 1 | The mesocircuit model. A common mechanism for downregulation of the anterior forebrain mesocircuit in severe brain injuries. Reduction of thalamocortical and thalamostriatal outflow following deafferentation and loss of neurons from the central thalamus withdraws important afferent drive to the medium spiny neurons of the striatum, which may then fail to reach firing threshold because of their requirement for high levels of synaptic background activity. Loss of active inhibition from the striatum allows neurons of the globus pallidus interna to tonically fire and provide active inhibition to their synaptic targets, including relay neurons of the already strongly disfacilitated central thalamus, and possibly also the projection neurons of the pedunculopontine nucleus.

A study utilizing transcranial magnetic stimulation (TMS) has found evidence for a graded measure of consciousness in normal individuals and patients with DOC. Rosanova, Gosseries and colleagues ${ }^{37}$ employed highdensity EEG to measure waves of brain activity induced by TMS pulses. In normal individuals, time-averaging of the EEG signal after each repetitive TMS pulse generates a reproducible wave pattern of activity that correlates with unconscious brain states, including non-REM sleep and pharmacologically induced coma. In unconscious, vegetative patients, the TMS responses tend to be very locally generated, or are more widespread but stereotypical and dynamically simple. Healthy controls in the wakeful conscious state, or during REM sleep, demonstrate complex, longer-lasting EEG responses to TMS.

Casali, Gosseries et al..$^{36}$ devised a novel empirical measure, the perturbational complexity index (PCI), to quantify these TMS-EEG responses, and have demonstrated its potential as a unified measurement scale to grade the level of consciousness. The PCI incorporates the theoretical requirement that wakeful consciousness involves integration of information across multiple brain regions, with highly differentiated activity occurring locally within separate regions. The PCI is a normalized measure that shows high values only if the initial TMS perturbation alters activity in a large set of integrated brain regions, each of which then reacts differently over time. In studies of patients with DOC, a graded increase in PCI values was demonstrated across individuals with different levels of consciousness.

\section{Common pathophysiological mechanisms}

DOC can be framed in the context of basic mechanisms underlying the state of neurons within the cerebral cortex, thalamus and striatum, and at the circuit level of network mechanisms. All severe brain injuries produce widespread deafferentation and reduced input to neurons across the corticothalamic system. At one extreme, if all inputs to the cerebral cortex are removed, only very low-frequency electrical activity (or none at all) may be seen. ${ }^{38}$ Typically, such complete or near-complete deafferentation is only seen in severe anoxic injuries, and most DOC arise in the setting of partially connected corticothalamic systems. Neurons in the cortex, thalamus and striatum are very sensitive to the amount of synaptic background activity that they receive, ${ }^{29,34,39}$ and can change patterns of firing or cease firing in response to small shifts in membrane potential. Patients with DOC might not demonstrate the necessary neuronal dynamics to establish brain activity states consistent with conscious awareness, which seem to require a sufficient number of connected neurons to be driven into a depolarized state that allows local processing and longrange synchronization with other brain regions. When such capacities are preserved in patients with DOC, the interplay between diurnal variations in neuromodulatory tone in the thalamus and cortex and the degree of deafferentation of large segments of the corticothalamic system probably accounts for often wide behavioural fluctuations.

A common circuit-level mechanism has been proposed to account for transitions across the DOC continuum. The mesocircuit model (Figure 1) posits that anterior forebrain function is markedly downregulated in all severe brain injuries as a result of widespread disconnection or neuronal death. A crucial role is proposed for neurons within the central thalamus that are known to show progressive deafferentation in proportion to the severity of structural brain injuries. ${ }^{40}$ At the mesocircuit level, broad reduction of corticostriatal, thalamocortical and thalamostriatal outflow is expected to produce sufficient loss of afferent input to the medium spiny neurons (MSNs) of the striatum to prevent these neurons from reaching their firing threshold. ${ }^{34}$ A combination of effects of direct deafferentation of central thalamic neurons and active inhibition of some of these cells by the globus pallidus interna, as a result of the loss of their active inhibition from the MSNs in the striatum, conspire to produce broad reductions in global cerebral synaptic activity, as reflected in the very low cerebral metabolic rates that are typical in patients with DOC. ${ }^{1}$

Expressed behaviour and level of conscious content increase with restoration of normal patterns of activity in the anterior forebrain mesocircuit. ${ }^{41}$ The mesocircuit model also offers a unifying account of the effects of several activating medications used in DOC and novel strategies such as deep brain stimulation (DBS), all of which have the first-order effect of restoring activity of frontal cortical, striatal and central thalamic neurons and releasing organized behaviours. In addition, the model draws a direct connection across similar shifts in frontal cortical and striatal activation during the sleep-wake cycle, and paradoxical behavioural activation observed during the early stages of anaesthesia. ${ }^{35,41}$ 
Several specific predictions of the mesocircuit model have been supported by recent studies. Importantly, stronger downregulation of anterior forebrain activity measured via EEG in zolpidem-responsive individuals across the aetiological spectrum of brain injuries is consistent with the model. ${ }^{42}$ Similarly, activation of high-frequency $15-40 \mathrm{~Hz}$ activity over frontocentral regions in association with the zolpidem response, ${ }^{42}$ on spontaneous recovery from severe brain injuries, ${ }^{43}$ and with electrical stimulation of the central thalamus ${ }^{44}$ all support predictions of the model. In addition, a study of 32 patients with severe injuries demonstrated a reversal of globus pallidus and central thalamic resting metabolic signals, satisfying a key prediction of the model. ${ }^{45}$ The mesocircuit model also predicts that activation of the central thalamic neuronal population is a final common pathway supporting a downregulated anterior forebrain in severe brain injuries, and thus offers a mechanism for the response to central thalamic DBS. ${ }^{46}$

\section{Diagnostic challenges}

Diagnostic accuracy is critical to designing an appropriate plan of care, establishing an accurate prognosis, and providing appropriate information to caregivers. ${ }^{19,47}$ Unfortunately, diagnostic error is common among patients with VS and MCS. Reports consistently find that approximately $30-40 \%$ of people diagnosed with VS actually retain conscious awareness. ${ }^{48-50}$ Misdiagnosis may contribute to premature withdrawal of life-sustaining care and lead to inappropriate medical management (for example, neglect of pain treatment). The risks associated with early misdiagnosis are highlighted by a Canadian study, which found that $70 \%$ of the deaths reported in six level I trauma centres were attributable to withdrawal of life-sustaining therapy, with half occurring within the first $72 \mathrm{~h}$ of injury. ${ }^{51}$ The failure to detect conscious awareness may also limit access to specialized neurorehabilitative services, as many insurance policies will not authorize admission to a rehabilitation programme for individuals believed to be unconscious.

The lack of a 'gold standard' for detection of conscious awareness is the most prominent confounding factor for diagnostic assessment. In the absence of an objective test of consciousness, diagnostic impressions are based on behavioural observations at the bedside. Behaviour is, however, an unreliable proxy for consciousness. ${ }^{19,52}$ Interpretation of the significance of a specific behaviour reflects the subjective bias of the observer and is a byproduct of the range of behaviours sampled (narrow versus broad), the frequency of assessments performed (one-off versus serial), and the parameters established for response interpretation (qualitative versus operationally defined).

A second source of diagnostic error arises from patientspecific characteristics. Underlying peripheral and cortical sensory deficits, neuromuscular impairments, fluctuations in arousal level, cognitive dysfunction, subclinical seizure activity, and occult illness may all mask conscious awareness. ${ }^{19,52}$ Environmental factors that constrain the patient's behavioural response repertoire-for example, use of restraints or sedating medications-may also bias the diagnostic impression.

Various approaches have been employed to discern levels of consciousness in behaviourally non-responsive and non-communicative patients. Neurobehavioural assessment methods are most commonly employed in clinical practice, in view of their availability, low cost and ease of use. Structural and functional neuroimaging strategies and electrophysiological techniques have garnered scientific and clinical attention in light of increasing evidence that they can detect active cognitive processing in the absence of behavioural signs of consciousness. ${ }^{53-55}$

\section{Behavioural assessment}

\section{Neurobehavioural rating scales}

Neurobehavioural rating scales rely on standardized administration and scoring procedures to detect subtle but important behavioural signs of consciousness. Scales designed for this purpose have generally been shown to have good reliability and validity, although other important psychometric properties such as sensitivity and specificity, and positive versus negative predictive value, have not been adequately investigated. An evidence-based review of neurobehavioural rating scales designed specifically for patients with DOC was recently completed by a task force of the American Congress of Rehabilitation Medicine. The task force identified six scales (of the 13 reviewed) that seem to be sensitive for detecting conscious awareness (Table 2$).{ }^{50}$ The Coma Recovery Scale-Revised (CRS-R $)^{56}$ received the strongest recommendation ("minor reservations") of those reviewed, on the basis of psychometric properties deemed important for clinical assessment.

\section{IQBA}

Individualized quantitative behavioural assessment (IQBA) employs single-subject experimental design to address case-specific questions, and is intended to complement comprehensive neurobehavioural assessment. This method of assessment is particularly useful when behavioural responses are ambiguous or infrequent. ${ }^{49,57}$

In IQBA, behaviours of interest are operationally defined and tested under varying conditions constructed to address a specific question. For example, one can ask whether movement of the thumb is volitional by testing the frequency of thumb movement following a command to move the thumb (volitional condition) or another part of the body (noise condition), and in the absence of any command (rest condition). Differences in the frequency of the target behaviour can then be tested statistically to determine whether the rate of occurrence is significantly greater in one condition relative to the others. If the analysis indicates that the frequency of movement is significantly higher in the volitional condition relative to the noise and rest conditions, the behaviour is very likely to be under volitional control. ${ }^{57,58}$ IQBA can be adapted to address a broad range of questions and has been shown to be useful for detection of commandfollowing, visual field deficits, hemispatial neglect, and medication effects. ${ }^{59-61}$ 


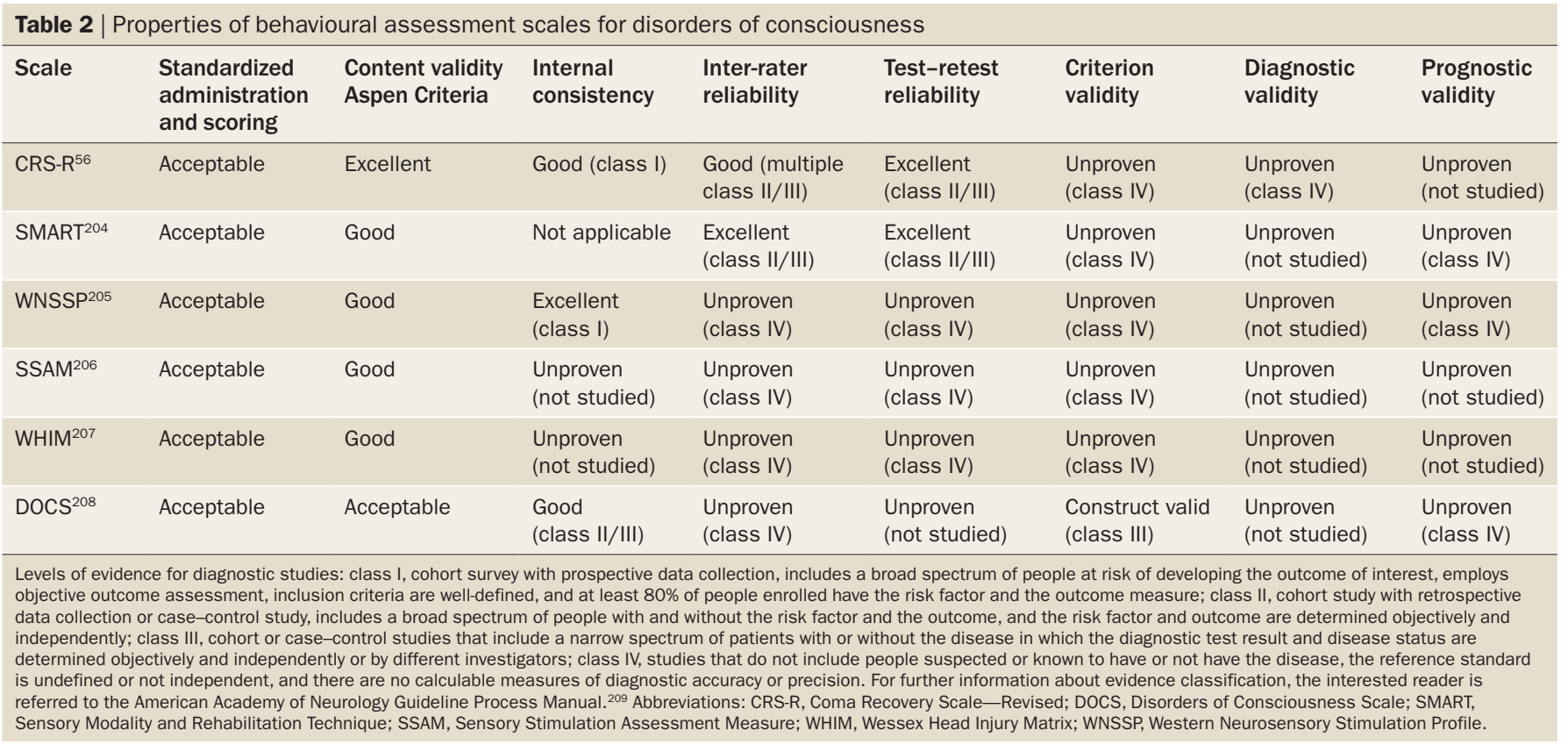

\section{Neuroimaging strategies}

While behavioural assessment of DOC remains the gold standard, neuroimaging permits objective documentation of CNS damage after acquired brain injury. From a scientific standpoint, neuroimaging studies aid our understanding of the neural correlates of human consciousness. From a clinical perspective, they provide additional information concerning diagnosis, prognosis and the course of recovery of consciousness, and can serve as surrogate markers for novel therapeutic interventions.

\section{Structural imaging}

MRI is the method of choice to visualize the location and extent of brain damage in chronic DOC. In the acute setting, however, CT scanning may be preferred, owing to its accessibility, speed of acquisition, and sensitivity to acute haemorrhage or lesions that require immediate surgery. ${ }^{62}$ Standard T1-weighted structural MRI assessments cannot reliably differentiate VS from MCS, but voxel-based morphometry analyses may allow this distinction in the near future. Older studies have shown the possible prognostic value of 'classic' structural MRI sequences to predict DOC outcome; for example, the presence of corpus callosum and dorsolateral brainstem lesions correlates with lack of recovery at the group level. ${ }^{63}$ However, recently developed quantitative diffusion tensor imaging (DTI) techniques, which permit assessment of structural white matter damage, have been shown to outperform clinical markers in predicting 1-year functional outcome at the individual-patient level in patients with traumatic ${ }^{64}$ or anoxic ${ }^{65}$ brain injury. In our view, DTI-MRI techniques offer a unique opportunity to quantify the structural integrity of the white matter, and can also quantify the primary and secondary axonal damage encountered in DOC. ${ }^{66}$

\section{Functional neuroimaging}

Key advances in our understanding of DOC have come from the use of functional imaging. Depending on the technique employed, functional neuroimaging can measure the brain's metabolic activity (for example, by use of ${ }^{18} \mathrm{~F}$-fluorodeoxyglucose PET, [FDG-PET] or MRI spectroscopy), haemodynamic activity (for example, by use of $\mathrm{H}_{2}{ }^{15} \mathrm{O}$-PET or functional MRI [fMRI]) or electrical activity (for example, EEG, evoked potentials or magnetoencephalography). Depending on the acquisition conditions, these approaches can measure resting or active brain function, the latter through either passive external stimulation or active cognitive paradigms.

\section{PET imaging}

FDG-PET studies in 'resting state' conditions were the first to demonstrate massive decreases in brain metabolism in DOC. In VS, FDG-PET classically shows a reduction of brain function to $40-50 \%$ of normal values. ${ }^{1}$ Voxel-based studies indicated that the lateral and medial frontoparietal associative cortices are the most hypometabolic areas, ${ }^{67}$ and recovery of consciousness seems to be characterized by recovery of activity in this frontoparietal 'awareness network. ${ }^{68}$ More-recent studies have used automated classifiers for the analysis of FDG-PET data, permitting calculation of the probability that individual patients are conscious ('locked in') or unconscious (VS) ${ }^{69}$ At the single-patient level, FDG-PET cannot disentangle VS from MCS, but group studies have shown that CRS-R total scores correlate with metabolic activity in the awareness network. ${ }^{70}$ Within this network, frontoparietal midline structures are thought to be important for internal, stimulus-independent or 'self' consciousness, whereas lateral frontoparietal cortices seem to be critical for external or sensory awareness. ${ }^{71}$ The latter network seems to be relatively preserved in 


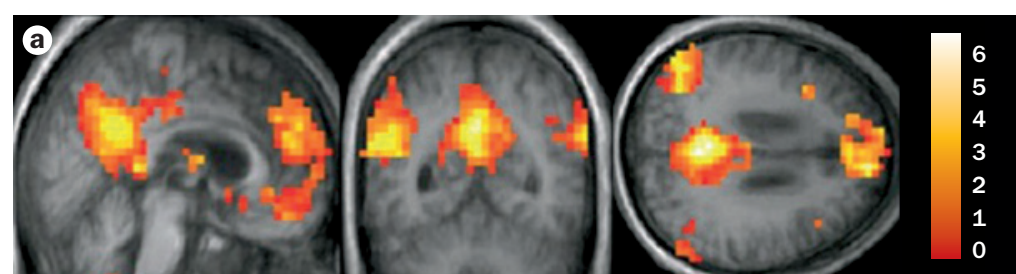

b
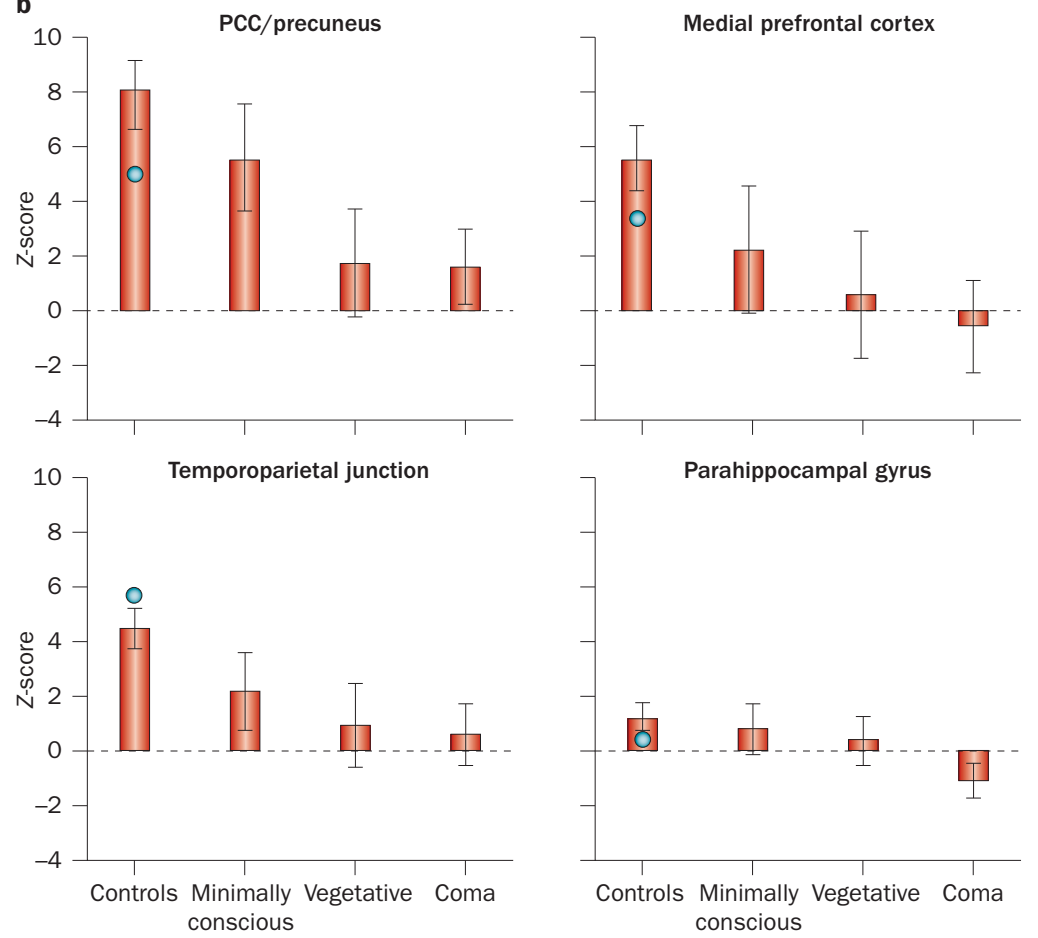

Figure 2 | DMN connectivity correlates with level of consciousness. a | Areas showing a linear correlation between DMN connectivity and consciousness levels, ranging from healthy controls, to minimally conscious, vegetative then comatose patients. Results are rendered on the mean T1 structural image of the patients. b $\mid$ Mean z-scores and $90 \% \mathrm{Cl}$ for DMN connectivity in $\mathrm{PCC} /$ precuneus, temporoparietal junction, medial prefrontal cortex and parahippocampal gyrus across patient populations. Locked-in syndrome patient $z$-scores are displayed for illustrative purposes as additional blue circles overlaid on control population data. Abbreviations: DMN, default mode network; PCC, posterior cingulate cortex. Vanhaudenhuyse, A. et al., Default network connectivity reflects the level of consciousness in non-communicative brain-damaged patients, Brain 133, 161-171 (2010), by permission of Oxford University Press.

MCS (compared with VS), possibly reflecting recovery of voluntary interaction with the environment. ${ }^{70}$ Patients who are considered to be in MCS because they display nonreflexive behaviour but fail to follow commands (a condition newly termed MCS-MINUS) ${ }^{72,73}$ have been shown to have metabolic dysfunction in the dominant left-hemispheric language network, ${ }^{74}$ possibly related to the presence of aphasia.

$\mathrm{H}_{2}{ }^{15} \mathrm{O}$-PET studies suggest that VS represents a global disconnection syndrome in which the awareness networks are functionally disconnected from primary cortical areas. ${ }^{75,76}$ By contrast, patterns of activation observed in patients in MCS indicate preservation of large-scale cortical networks associated with auditory $y^{77,78}$ and pain ${ }^{79}$ processing.

\section{Functional MRI}

In recent years, PET activation studies have been largely superseded by non-ionizing fMRI techniques. Activation fMRI studies using auditory, tactile or visual stimuli have shown near-normal high-level cortical activation in MCS and low-level activation in VS (reviewed elsewhere ${ }^{1}$ ). The minority of patients in VS who exhibited high-level activation often showed clinical signs of recovery at long-term follow-up. ${ }^{80-82}$ Despite their potential value as prognostic markers, the diagnostic value and interpretation of activation fMRI studies in DOC in terms of the presence or absence of residual consciousness have remained controversial. Indeed, in the absence of a full understanding of the neural correlates of consciousness, deficient cortical activation to external stimuli does not necessarily prove the absence of consciousness. ${ }^{83}$

'Active' fMRI paradigms have been developed to probe for possible motor-independent signs of commandfollowing. ${ }^{84}$ Patients with DOC are asked to perform cognitive tasks in motor (for example, "imagine playing tennis"), visuospatial (for example, "imagine walking around in your house") or visual (for example, "look at the face") domains. ${ }^{21,85-89}$ This approach provided an opportunity to ask yes-no questions to a patient with an initial clinical diagnosis of VS (but later shown to be in MCS) ${ }^{85}$ It should be stressed, however, that many of the tested patients in MCS who showed behavioural signs of command-following failed to show a response to these active fMRI tests, leading to false-negative findings. Because this approach depends on adequate processing and performance of the cognitive task, these paradigms cannot document residual consciousness in patients with severe sensory, cognitive or language impairment. ${ }^{90}$

Task-free 'resting-state' blood oxygen level-dependent (BOLD) fMRI measurements have also been performed in DOC. ${ }^{91,92}$ Recording of spontaneous fluctuations in BOLD fMRI activity under unstimulated conditions has identified various functional networks, some of which are thought to represent conscious cognitive activity. ${ }^{71,93,94}$ The best-studied network is the default mode network (DMN) encompassing the posterior and anterior cortical midline structures, which are considered to be involved in stimulus-independent thought, mind-wandering and self-consciousness. ${ }^{95}$ The DMN was shown to be absent in brain death, ${ }^{96}$ but still partially preserved in VS, ${ }^{97-99}$ probably reflecting residual structural connectivity. ${ }^{93}$ At the group level, resting-state network activity revealed reduced interhemispheric connectivity ${ }^{100}$ and correlated with levels of consciousness in patients with DOC (Figure 2).$^{97}$ At the single-patient level, however, it fails to reliably distinguish VS from MCS, and contamination by motion or other artefacts can impede the identification of true neuronal activity. ${ }^{99}$

The arterial spin labelling (ASL) technique allows noninvasive measurement of resting-state cerebral blood flow. A recent ASL-MRI study in patients in MCS showed a profound decrease in blood flow in anterior cortical midline structures. ${ }^{101}$ Finally, MRI spectroscopy, a measure of biochemical changes in the brain, has uncovered severe metabolic cortical ${ }^{102}$ and thalamic ${ }^{103}$ neuronal dysfunction in DOC, with probable prognostic value. ${ }^{104,105}$ 


\section{Electrophysiology}

In the DOC context, EEG can be used to predict outcome, evaluate residual cognitive function, detect consciousness, and provide a means to communicate with the outside world without using muscular channels. ${ }^{106,107}$ In coma, visual analysis of EEG recordings can identify epileptiform activity, guide treatment, and help establish prognosis (especially in anoxic cases). ${ }^{108,109}$ In DOC, visual analysis of the EEG classically shows global slowing of electrogenesis but fails to differentiate VS from MCS or predict outcome. Quantitative EEG (qEEg) techniques process the data and retrieve features not visible on the raw traces. qEEG has shown group-level differences between VS and MCS in time domain, power spectrum, connectivity, ${ }^{110,111}$ entropy ${ }^{112}$ and bispectral index ${ }^{13,114}$ measurements, but does not presently offer reliable diagnostic or prognostic information at the single-patient level.

Long-duration EEG monitoring permits evaluation of the important interaction between arousal and consciousness in DOC. ${ }^{115}$ A 24-h polysomnography study observed behavioural (eyes open or closed) but not electrophysiological sleep-wake patterns in VS. ${ }^{116}$ Using high-density EEG, a homoeostatic decline of EEG slow-wave activity through the night (possibly reflecting residual synaptic plasticity) and periods of REM sleep (possibly reflecting 'dreaming') could be demonstrated in MCS but not in VS. ${ }^{17}$

Event-related potentials (ERPs) are averaged EEG epochs to external or cognitive events. ${ }^{118}$ In comatose patients, the absence of a cortical response to electrical stimulation of the median nerves during somatosensory ERP recordings is associated with poor outcome, especially after anoxic injury, ${ }^{119}$ although treatment by hypothermia might challenge the prognostic utility of this approach. Preliminary ERP data show some prognostic value in patients with chronic DOC. ${ }^{118}$ Brainstem auditory ERPs to a stream of simple beeps are not very informative in the diagnosis or prognosis of DOC. By contrast, auditory oddball ERPs, which detect processing of novelty or sound deviance, may help predict good outcome in coma and other DOCs. ${ }^{120}$ Auditory stimuli with emotional or autoreferential valence (such as the patient's own name) are more powerful in eliciting a cortical response than are neutral beeps, and their presence may have prognostic value ${ }^{121}$ even if it does not necessarily reflect conscious processing. ${ }^{122}$

An elegant attempt to develop auditory ERP markers of conscious processing can be achieved through measurement of cerebral responses to violations of temporal regularities that are both local in time and global across several seconds. Local violations lead to an early response in auditory cortex, independent of attention and, probably, consciousness. Despite the presence of many false negatives, global violations lead to a late and spatially distributed response that only seems to be present when patients are at least minimally conscious. ${ }^{123,124}$ In addition, novel effective connectivity measurements of classic auditory mismatch negativity ERP paradigms allow assessment of top-down processes involved in recurrent neuronal message-passing and the generation of long-latency electrophysiological responses, providing another possible correlate of conscious perception in DOC. ${ }^{125}$

As in fMRI, ERP recordings can be obtained in both passive and active paradigms. In one study, patients with DOC listened through headphones to a series of names including their own name or other names, in both passive and active conditions. ${ }^{126}$ In the active condition, patients were instructed to count the number of times they heard their own name or another target name, and the increase in P3 amplitude (known to depend on attention) was taken as a marker of response. This approach led to detection of consciousness in a rare case of total LIS. ${ }^{127}$ An earlier case involving a patient with total LIS secondary to amytrophic lateral sclerosis also successfully used ERP recordings for detection of active cognition. ${ }^{128}$ Other studies have used motor imagery to detect command-related EEG changes in MCS ${ }^{129}$ and some rare VS cases ${ }^{130}$ in the absence of overt motor behaviour. An independent re-analysis of the data from the latter study, ${ }^{131}$ however, identified statistical flaws and failed to reproduce the initial findings, illustrating the challenge of developing reliable statistical classifiers of ERP data in DOC. Indeed, in the absence of a gold standard for measuring consciousness, ${ }^{19,83}$ active functional neuroimaging or neurophysiological tools must strike a balance between avoidance of false-positive and false-negative errors.

Conversion of active EEG paradigms (also referred to as brain-computer interface $[\mathrm{BCI}]$ technology) into a reliable communication tool in the context of DOC remains challenging. ${ }^{132}$ Most BCI systems have been developed for paralysed or LIS patients, but may not work in MCS because of fluctuations in vigilance and limitations in attention span. For example, a four-choice auditory oddball EEG-BCI paradigm, which had been validated in healthy controls and cognitively intact patients with LIS, revealed reliable command-following in a patient in MCS but could not be converted into a functional communication system. ${ }^{133}$ Also, non-EEG-based systems, such as measurement of subclinical electromyography (EMG) signals, ${ }^{134}$ pupil dilation during mental calculation ${ }^{135}$ or changes in salivary $\mathrm{pH},{ }^{136} \mathrm{can}$ be used to identify covert signs of command-following in DOC.

\section{Transcranial magnetic stimulation}

TMS of the motor cortex, coupled with EMG response detection (that is, motor ERPs) is used to assess cortical excitability, which is decreased in DOC and correlates with level of consciousness. ${ }^{137}$ TMS coupled to simultaneous EEG recordings is a promising method to assess cerebral effective connectivity and consciousness ${ }^{138}$ while bypassing subcortical afferent and efferent pathways, and does not require active participation or language comprehension. In VS, TMS has been shown to trigger a simple, local EEG response, similar to deep sleep or anaesthesia. ${ }^{37}$ In MCS, TMS-EEG shows complex activations that involve distant cortical areas, similar to LIS and conscious controls. ${ }^{37}$ Longitudinal PCI measurements 
Table 3 | Strengths and limitations of neuroimaging and electrophysiological techniques in DOC

\begin{tabular}{|c|c|c|c|c|c|c|c|c|}
\hline Technique & $\begin{array}{l}\text { Measurement } \\
\text { type }\end{array}$ & Strengths & Limitations & $\begin{array}{l}\text { Spatial } \\
\text { resolution }\end{array}$ & $\begin{array}{l}\text { Temporal } \\
\text { resolution }\end{array}$ & $\begin{array}{l}\text { Level of } \\
\text { experience } \\
\text { required }\end{array}$ & Cost & Availability \\
\hline FDG-PET & Metabolic & $\begin{array}{l}\text { Relatively direct measure } \\
\text { of neuronal energy use } \\
\text { (glucose uptake) }\end{array}$ & $\begin{array}{l}\text { lonizing (limited } \\
\text { repeated measures) }\end{array}$ & + & -- & ++ & ++ & -- \\
\hline $\begin{array}{l}\text { Functional } \\
\text { MRI }\end{array}$ & $\mathrm{CBF}$ & $\begin{array}{l}\text { Permits both high-resolution } \\
\text { structural imaging of grey and } \\
\text { white matter (DTI) and } \\
\text { functional imaging } \\
\text { (spectroscopy, resting, passive } \\
\text { and active CBF paradigms) }\end{array}$ & $\begin{array}{l}\text { Sensitive to movement artefacts } \\
\text { requiring sedation/anaesthesia } \\
\text { Incompatible with ferromagnetic } \\
\text { material (derivation, pumps, } \\
\text { electrodes) }\end{array}$ & ++ & - & + & + & + \\
\hline EEG/ERPs & Electrical & $\begin{array}{l}\text { Easy, repeatable, portable } \\
\text { and cheap }\end{array}$ & $\begin{array}{l}\text { Muscle, eye and dysautonomia } \\
\text { artefacts } \\
\text { Challenging source reconstruction }\end{array}$ & -- & ++ & + & - & ++ \\
\hline EEG-TMS & Electrical & $\begin{array}{l}\text { Stereotaxic stimulation } \\
\text { connectivity studies }\end{array}$ & $\begin{array}{l}\text { Stimulation areas limited by } \\
\text { muscle artefacts }\end{array}$ & $(-)$ & ++ & ++ & + & -- \\
\hline
\end{tabular}

performed in patients who recovered consciousness revealed a clear-cut change in TMS-EEG connectivity and complexity measures, sometimes occurring before clinical communication could be established. ${ }^{36}$

\section{Strengths and limitations}

Each of the neuroimaging approaches described above has advantages and limitations relating to the type of measurement, degree of spatiotemporal resolution, level of expertise required, and cost and availability. Table 3 summarizes the strengths and weaknesses of these procedures.

\section{Treatment interventions}

Clinical management of patients with DOC has two primary aims: prevention of secondary medical complications and restoration of cognitive-behavioural functions. Medical complications can arise as a direct result of the brain injury (for example, development of contractures), as an indirect consequence of the injury (for example, aspiration pneumonia), or as the result of treatment (for example, sedative effects of analgesics). Restorative interventions focus on promoting recovery of consciousness, communication and functional competency.

\section{Prevention and management of complications}

The incidence of medical complications in patients with DOC undergoing rehabilitation during the first 16 weeks post-injury is high, resulting in rehospitalization in approximately $15 \%$ of events. ${ }^{139}$ Whyte et al. followed 181 rehabilitation inpatients in traumatic VS or MCS over a 6-week period, and found the median number of medical complications experienced per patient to be 2 (range $0-9$ ). ${ }^{140}$ The five most common complications were hypertonia/spasticity $(8.3 \%)$, urinary tract infection (6.4\%), agitation/aggression (6.4\%), sleep disturbance (6.2\%), and hyperkinesia/motor restlessness (4.7\%). Pneumonia was relatively infrequent (3\%) but was typically rated as severe, and was the most common reason for acute-care transfer.
Infection, dysautonomia, neuromuscular dysfunction, hydrocephalus, seizures, shunt malfunctions and other complications in patients with DOC require early detection and aggressive management with medical, orthopaedic and rehabilitation procedures. Prophylactic treatments should be initiated to prevent high-risk complications, including deep vein thrombosis, cardiac problems, hypercholesterolaemia, hypertension and hypotension, and diabetes. Neuromuscular complications can be effectively managed with intrathecal baclofen pumps, botulinum toxin, nerve and muscle blocks, oral antispasmodics, and physical interventions including ice, heat and vibration. ${ }^{141-144}$ Aggressive pain management should always be initiated for patients in MCS,,$^{7,145-147}$ as their capacity for subjective awareness of pain is preserved.

\section{Enhancement of recovery}

A wide array of behavioural, pharmacological and other rehabilitation-oriented treatments are routinely administered in patients with DOCs, but few interventions have been rigorously shown to accelerate or enhance functional recovery, ${ }^{148}$ owing in part to the logistical and methodological difficulties of conducting placebocontrolled trials in this population. ${ }^{149}$ Here, we review the treatments used to enhance arousal level, drive, communication ability, and executive control processes.

\section{Physical management strategies}

Physical medicine procedures are routinely employed in patients with DOC on the premise that strengthening and conditioning exercises can maximize recovery of spared neurological functions. This approach relies on traditional physical therapy techniques and includes passive range-of-motion exercises, prolonged muscle stretch, serial casting, and positioning protocols. A review of 17 studies involving paediatric patients in VS or MCS concluded that the available evidence for the effectiveness of treatments for spasticity and reduced range of motion was inconclusive. ${ }^{144}$ By contrast, a retrospective study of 38 individuals with initial 
Glasgow Coma Scale scores $<9$ found that ratings on the Levels of Cognitive Functioning Scale ${ }^{150}$ and the percentage of home discharges were significantly higher for the 17 patients who received an aggressive, formal programme of multidisciplinary rehabilitation during the acute hospitalization, as compared with 21 patients who received no formal rehabilitative treatment. ${ }^{151}$

\section{Pharmacological interventions}

Two medications intended to modulate key neurotransmitter systems that mediate arousal, attention and drive functions have demonstrated effectiveness in randomized clinical trials. Giacino, Whyte and colleagues administered amantadine or placebo for 4 weeks to 184 rehabilitation inpatients who were in VS or MCS at 4-16 weeks post-injury. ${ }^{2}$ Participants received 200-400 mg of the study drug depending on the degree of change detected weekly on the Disability Rating Scale, ${ }^{152}$ followed by a 2 -week washout. ${ }^{2}$ During the 4 -week treatment period, rates of recovery were significantly faster in the amantadine group, regardless of whether patients were enrolled early (28-70 days) or late (71-112 days) post-injury, or whether they were in VS or MCS at baseline. The rate of improvement slowed significantly during the washout phase, but the gains demonstrated in the amantadine group were maintained after treatment discontinuation. In addition, a greater proportion of the amantadine-treated patients recovered the ability to follow commands consistently, answer yes-no questions accurately, use objects in a functional manner, and speak intelligibly. After 4 weeks of treatment, 18\% of the amantadine group remained in VS, compared with $31 \%$ of the placebo group. These results provide strong support for the effectiveness of amantadine in accelerating the pace of recovery in patients with DOC.

Zolpidem, a selective omega- $1 \gamma$-aminobutyric acid (GABA) agonist with soporific properties, has been reported, paradoxically, to produce marked improvements in the consistency and complexity of behavioural responses in some patients with DOC. ${ }^{153-160}$ Whyte and Myers $^{157}$ conducted a placebo-controlled, double-blind, crossover trial in 15 patients who had been in VS or MCS for at least 1 month following traumatic or nontraumatic brain injury. Zolpidem $(10 \mathrm{mg})$ or placebo was administered in blinded order on two different occasions, separated by 1-7 days. Behavioural responses to standardized prompts from the CRS-R were recorded every hour for $5 \mathrm{~h}$ following each dose. The authors reported that one patient, who had been in traumatic VS for over 4 years, temporarily transitioned from VS to MCS following administration of zolpidem, but not placebo. Command-following, visual pursuit and automatic social gestures (for example, waving) re-emerged after receiving zolpidem on two separate occasions, but not after receiving placebo. The remaining 14 patients failed to show significant differences in response to zolpidem and placebo. A recent prospective open-label study also failed to find any significant improvement (that is, change in diagnosis) in a cohort of 60 chronic patients with DOC (31 with traumatic brain injury) ${ }^{161}$

\section{Central thalamic deep brain stimulation}

Central thalamic DBS (CT-DBS) is designed to modulate neural circuits that mediate arousal, attention and drive. ${ }^{41,162} \mathrm{~A}$ surgically implanted pulse generator delivers a train of electrical impulses to targeted nuclei within the central thalamus that are anatomically and physiologically specialized to control arousal, sustained attention, working memory, and motor intention networks. The objective is to activate viable cortical networks that have become downregulated as a result of mesodiencephalic dysfunction.

Schiff et al. devised a prospective, double-blind, alternating crossover design to test the effectiveness of CT-DBS in a small series of patients who had remained in MCS for over 12 months. ${ }^{46}$ Standardized outcome measures with pre-established reliability and validity were used to capture behavioural changes related to CT-DBS. In the initial case, a 36-year-old male who had been in post-traumatic MCS for over 6 years received bilateral CT-DBS in alternating 30-day on-off cycles for a 6-month period. During CT-DBS-on periods, significant improvements were observed in arousal level, functional movements of the upper extremities, and oral feeding. Behavioural performance in these domains decreased significantly during the CT-DBS-off periods, but remained well above baseline level, suggesting carryover effects. Functional gains were maintained across the 24-month open-label follow-up phase. While this case provides 'proof of principle' that DBS can promote meaningful behavioural improvement well after the accepted period of spontaneous recovery, predictors of response remain unknown and require further study.

\section{Other treatments}

A wide range of other treatments, including structured sensory stimulation, ${ }^{163}$ repetitive TMS, ${ }^{164}$ hyperbaric oxygen, ${ }^{165}$ and various dopaminergic and GABAergic medications, ${ }^{166}$ have been administered to patients with DOCs, but the evidence is insufficient to formulate recommendations regarding their use in clinical practice.

\section{Ethical and policy considerations Care context}

Despite considerable progress in the DOC research field, the care of many patients with these conditions remains inadequate. Patients with DOC continue to encounter a health-care system that views their condition as hopeless and beyond remediation. ${ }^{167}$ This pervasive nihilism-a legacy of the right-to-die movement, which first affirmed choice at life's end ${ }^{4}$ in cases such as Quinlan and Schiavo ${ }^{168,169}$-influences practice patterns, ${ }^{170}$ viewing patients with severe brain injury through an end-of-life prism, leaving them marginalized and sequestered from the evolving fruits of neuroscience (J. J. Fins, unpublished work). ${ }^{171}$

Institutional Review Board-approved interviews of families participating in research conducted at Weill Cornell Medical College and Liège University Hospital tell a counter-tale to the brilliant science that has been reviewed in the sections above (J. J. Fins, unpublished 
work). Outside elite centres, the status quo is grim, with families reporting a pervasive culture of neglect. Prognoses often lack nuance, and are invariably viewed as poor. Despite observations that $68 \%$ of patients with traumatic brain injury on inpatient rehabilitation services regained consciousness and, of those, close to $20 \%$ regained functional independence, ${ }^{8}$ families of patients in the acute care setting are routinely counselled to make decisions to withhold or withdraw life-sustaining therapies, pursue palliative care recommendations or consent to organ donation before a patient's prognosis-or even diagnosis-is clear (J. J. Fins, unpublished work). ${ }^{171-175}$

\section{Access to rehabilitation}

Patients who have neither died from their injuries nor succumbed to pressures to withhold or withdraw care face substantial challenges on discharge from hospital. If they remain in VS, they may be sent for 'custodial care', often to nursing homes or other facilities that are unable to handle medical conditions that can occur after severe brain injury, such as central hyperthermia (J. J. Fins, unpublished work). In these facilities, patients will not receive intensive rehabilitation, and might develop complications of immobility, including bedsores and decreased range of motion. Evolution of their condition to MCS, as is expected in $50 \%$ of traumatic brain injury cases, is likely to go unnoticed given the intermittent evidence of consciousness that a patient in MCS displays. ${ }^{176}$ The episodic nature of these behaviours, coupled with the expectations of clinicians in these settings, can cause family observations of behaviours suggestive of MCS to be ascribed to denial. One study reported a $41 \%$ rate of misdiagnosis of MCS as VS. ${ }^{48}$ Notable patients like Terry Wallis have been misdiagnosed as vegetative for decades, ${ }^{177}$ their true condition only being recognized when they recovered further and emerged from MCS. ${ }^{178}$

Patients who are candidates for rehabilitation will encounter eligibility requirements that severely limit access to care. As recently discussed by Whyte and Nakase-Richardson, ${ }^{179}$ the admission criteria of McKesson Health Solutions-a Fortune 500 company that works with insurance companies to develop utilization review and care pathways-would effectively deprive many patients with DOC of access to inpatient rehabilitation after hospital discharge. Following guidelines set out under McKesson's InterQual criteria, ${ }^{180}$ eligibility for acute inpatient rehabilitation would require that patients be at a level of 'Rancho III and evolving', which is equivalent to MCS and above. ${ }^{150,181}$ As noted by Whyte and NakaseRichardson, ${ }^{179}$ one problem with these criteria is that patients would have to demonstrate progress every day.

While it is readily appreciated that patients need to be interactive enough to participate in rehabilitation, and could, in theory, go to less-intensive care settings and be sent back to acute rehabilitation when they were ready, this rarely occurs in practice in both the USA and Europe. Whyte and Nakase-Richardson ${ }^{179}$ argue that the InterQual criteria keep patients from being properly assessed to see whether they could participate. The authors also note that 'evolving' implies too high a rate of progress, thereby excluding patients who are improving at a slower pace yet still retain the biological potential for significant recovery. An alternative 'front-loaded' model was proposed by the authors of the Mohonk Report, ${ }^{182}$ who suggested that patients should receive a period of acute rehabilitation after hospitalization, so as to enable full assessment by the skilled personnel best able to distinguish MCS from VS, and to identify patients who would benefit from rehabilitation. After a proper period of assessment and treatment, responders would continue in acute rehabilitation, whereas non-responders would be sent to subacute or chronic care venues. To date, these recommendations have not been accepted by USA policy makers and third parties (for example, McKesson).

For those patients who are admitted to inpatient rehabilitation, length of stay can be brief. In the USA, most spoke of 6-week courses of care, a time frame that can be inconsistent with the biological pace of recovery. ${ }^{183,184}$ Length of stay can be predetermined by insurance coverage or depend on bureaucratic models of care. In both the USA and many European countries (for example, the Netherlands), access to and reimbursement for ongoing rehabilitation is determined by a construct called medical necessity, which requires the behavioural demonstration of improvement to garner benefits. The benchmarks of progress that are used to determine medical necessity are inconsistent with MCS. For example, if a patient demonstrated an appropriate behaviour on a few occasions but failed to repeat that capability consistently, the first response would not be taken as evidence of progress. Episodic behaviours are inherent to the definition of MCS, highlighting the need for coverage metrics better suited to such conditions. ${ }^{73}$

A more integrated and comprehensive approach to care, linking academic medical centres, hospitals, acute inpatient rehabilitation and chronic care settings (as currently existing in some European countries, such as Belgium), has been proposed by the Mohonk Group, ${ }^{182}$ and implemented in part by the US Veterans Administration, ${ }^{185}$ but care remains fragmented for most patients once they leave rehabilitation. Truncated inpatient rehabilitation stays are particularly problematic because this might be the only course of rehabilitation that a patient obtains before placement in less-intensive settings. Patients are often lost to follow-up in chronic care when they would still benefit from rehabilitation services.

\section{Medicolegal and regulatory issues}

Research and treatment in patients in MCS is complicated by the lack of decision-making capacity. Inability to provide consent for research participation may lead to either surrogate authorization or outright prohibition of research without the patient's autonomous consent. The latter would generally be the case when the proposed research is more than minimal-risk and does not hold the prospect of direct medical benefit, such as in a phase I study. If consent cannot be obtained because of decisional incapacity, it would seem logical to expand the discretion of surrogates to make judgements about research participation-with proper safeguards and 
assurances-especially if the objective of the intervention is to restore autonomous voices to individuals with DOC (J. J. Fins, unpublished work). ${ }^{4,46,186-189}$

A related topic is the use of guardianship. Though designed to protect the interests of decisionally incapacitated patients, and to make decisions that are consistent with the patient's previously expressed wishes and values, guardianship designations can sometimes deprive patients of their rights. ${ }^{190,191}$ Given the financial resources and legal representation required to reverse a guardianship proceeding, guardianships can remain in place after a patient has regained decision-making capacity, thereby undermining patient autonomy and self-determination. ${ }^{192}$

Guardianship requirements can also promote dual agency, serving the interests of institutions rather than patients and families. One example encountered in the USA is that some states require a guardianship designation before a patient can be admitted to an inpatient rehabilitation hospital. This requirement helps to ensure that there is a legally responsible and fiscally accountable representative of the patient to assume the costs of care and responsibility for placement if benefits run out and discharge is required. The imposition of a guardianship requirement for admission could exacerbate health inequities by creating a barrier for the poor and legally underserved who may have difficulty obtaining the necessary legal representation for guardianship proceedings. ${ }^{193}$

Guardianship decisions can also be ethically problematic when the court intercedes and appoints a guardian over the objection of family members who perceive themselves as acting in the best interests of the patient. While courts can legitimately intercede to appoint a guardian when family discord exists, the situation becomes more complicated when the court's view of the patient's best interests conflicts with that of a unified family. Laws differ on this point depending on one's state and country. ${ }^{192}$ In jurisdictions where this kind of judicial intercession is consistent with prevailing law, the question arises of whether the court or the family is bestplaced to serve in this key role. The resolution of such questions requires knowledge of the particularities of an individual case combined with neutral adjudication.

For patients in MCS, what is fundamentally at stake is the recognition and cultivation of consciousness. Failure to recognize consciousness, encourage relationality and maximally integrate the patient into society by fostering functional communication could constitute a violation of the individual's civil rights (J. J. Fins, unpublished work). ${ }^{194}$

\section{Conclusions}

Innovations in the recording and processing of neuroimaging and electrophysiological data have produced a cornucopia of possibilities to assess the structure and function of the brain in DOC. In specialized centres, these methods are now being employed to map patterns of residual function and dysfunction, help reduce diagnostic errors between related conditions such as VS and MCS, and improve outcome prediction. ${ }^{195}$ The future integration of 'high-tech' brain measurements with existing clinical and behavioural methods of assessment should pave the way for new and innovative applications, and further elucidation of pathophysiological mechanisms could provide new opportunities for restoration of function through interventional neuromodulation. ${ }^{46,196}$ These emerging technologies also bring new ethical challenges, and have important implications for medicolegal decision-making. ${ }^{197}$

The novel neuroimaging and electrophysiological technologies await large-scale, multicentre validation studies. Future studies should also follow patients longitudinally and focus on multimodal imaging, ${ }^{198,199}$ combining and integrating information over time. ${ }^{200,201}$ These techniques can provide additional information to clarify the clinical significance of ambiguous behavioural signs, ${ }^{202}$ assess the effect of therapeutic interventions, and inform patient selection for clinical trials. The data should be combined with genomic information about neurochemical pathways and genetic polymorphisms linked to specific subtypes of DOC, ultimately leading to better and more-rational treatment and patient care.

Despite the rapidly growing body of evidence indicating that a substantial percentage of patients with DOC recover over time, a belief prevails that these disorders are hopeless and attempts to treat them futile. Consequently, many individuals with DOC are transferred directly from high-intensity acute care facilities to custodial settings that are ill-equipped to provide the necessary level of specialized assessment and treatment. A pressing need exists to develop a fully integrated system of care that is responsive to the complex needs of patients with DOC across the different phases of recovery. To this end, new health-care service delivery models must be developed that link academic medical centres, acute care and neurorehabilitation hospitals, and chronic care settings.

In conclusion, findings from neuroimaging and electrophysiology have identified new ways to assess awareness in DOC, and have revealed astounding cases of awareness in the setting of behavioural unresponsiveness. As a consequence, diagnostic classification systems are being rewritten, prognostic knowledge is improving, and therapeutic studies have regained momentum, causing a paradigm shift that is beginning to put an end to the era of therapeutic nihilism. ${ }^{203}$

Review criteria
We searched the MEDLINE database for English-language
reports published up to October 2013 that used the
terms "disorders of consciousness", "vegetative
state", "minimally conscious state", "neuroimaging",
"MRI", "PET", "EEG", "diagnosis", "rehabilitation"
and "outcome". We reviewed the full text of all original
articles, reviews, early-release publications and
associated citations retrieved, and relevant papers
maintained in the authors' own files. Articles were
selected for inclusion on the basis of their topical
representativeness and methodological rigour, as judged
by the authors and by journal impact factor.


1. Laureys, S. \& Schiff, N. D. Coma and consciousness: paradigms (re)framed by neuroimaging. Neuroimage 61, 478-491 (2012)

2. Giacino, J. T. et al. Placebo-controlled trial of amantadine for severe traumatic brain injury. N. Engl. J. Med. 366, 819-826 (2012).

3. Fins, J. J. Constructing an ethical stereotaxy for severe brain injury: balancing risks, benefits and access. Nat. Rev. Neurosci. 4, 323-327 (2003).

4. Schiff, N. D., Giacino, J. T. \& Fins, J. J. Deep brain stimulation, neuroethics, and the minimally conscious state: moving beyond proof of principle. Arch. Neurol. 66, 697-702 (2009).

5. James, W. The physical basis of emotion. Psychol. Rev. 1, 516-529 (1894).

6. Schiff, N. D. \& Plum, F. The role of arousal and "gating" systems in the neurology of impaired consciousness. J. Clin. Neurophysiol. 17, 438-452 (2000).

7. Giacino, J. T. \& Kalmar, K. The vegetative and minimally conscious states: a comparision of clinical features and functional outcome. J. Head Trauma Rehabil. 12, 36-51 (1997).

8. Nakase-Richardson, R. et al. Longitudinal outcome of patients with disordered consciousness in the NIDRR TBI Model Systems Programs. J. Neurotrauma 29, 59-65 (2012).

9. Plum F. \& Posner, J. The Diagnosis of Stupor and Coma, $3^{\text {rd }}$ edn (F. A. Davis, 1982).

10. [No authors listed] Medical aspects of the persistent vegetative state (1). The Multi-Society Task Force on PVS. N. Engl. J. Med. 330, 1499-1508 (1994).

11. Choi, S. C. et al. Temporal profile of outcomes in severe head injury. J. Neurosurg. 81, 169-173 (1994)

12. Dubroja, I., Valent, S., Miklic, P. \& Kesak, D. Outcome of post-traumatic unawareness persisting for more than a month. J. Neurol. Neurosurg. Psychiatry 58, 465-466 (1995).

13. Giacino, J. T. \& Kalmar, K. Diagnostic and prognostic guidelines for the vegetative and minimally conscious states. Neuropsychol. Rehabil. 15, 166-174 (2005).

14. Giacino, J. T. et al. The minimally conscious state: definition and diagnostic criteria. Neurology 58, 349-353 (2002).

15. Jennett, B., Adams, J. H., Murray, L. S. \& Graham, D. I. Neuropathology in vegetative and severely disabled patients after head injury. Neurology 56, 486-490 (2001).

16. Cairns, H., Oldfield, R. C., Pennybacker, J. B. $\&$ Whitteridge, D. Akinetic mutism with an epidermoid cyst of the $3^{\text {rd }}$ ventricle. Brain 64 , 273-290 (1941).

17. Nagaratnam, N., Nagaratnam, K., Ng, K. \& Diu, P. Akinetic mutism following stroke. J. Clin. Neurosci. 11, 25-30 (2004).

18. Fisher, C. M. Honored guest presentation: abulia minor vs. agitated behavior. Clin. Neurosurg. 31, 9-31 (1983).

19. Giacino, J. T. et al. Behavioral assessment in patients with disorders of consciousness: gold standard or fool's gold? In Coma Science: Clinical and Ethical Implications (eds Laureys, S. et al.) 33-48 (Elsevier, 2009).

20. Giacino, J. T. Disorders of consciousness: differential diagnosis and neuropathologic features. Semin. Neurol. 17, 105-111 (1997).

21. Rodriguez Moreno, D., Schiff, N. D., Giacino, J. Kalmar, K. \& Hirsch, J. A network approach to assessing cognition in disorders of consciousness. Neurology 75, 1871-1878 (2010).

22. Laureys, S. et al. The locked-in syndrome: what is it like to be conscious but paralyzed and voiceless? Prog. Brain Res. 150, 495-511 (2005).
23. Formisano, R., Pistoia, F. \& Sarà, M. Disorders of consciousness: a taxonomy to be changed? Brain Inj. 25, 638-639 (2011).

24. Smart, C. M. et al. A case of locked-in syndrome complicated by central deafness: Nat. Clin. Pract. Neurol. 4, 448-453 (2008).

25. Sherer, M., Nakase-Thompson, R., Yablon, S. A. \& Gontkovsky, S. T. Multidimensional assessment of acute confusion after traumatic brain injury. Arch. Phys. Med. Rehabil. 86 896-904 (2005).

26. Sherer, M., Yablon, S. A., Nakase-Richardson, R. \& Nick, T. G. Effect of severity of post-traumatic confusion and its constituent symptoms on outcome after traumatic brain injury. Arch. Phys. Med. Rehabil. 89, 42-47 (2008).

27. Parvizi, J. \& Damasio, A. Consciousness and the brainstem. Cognition 79, 135-160 (2001).

28. Saper, C. B., Scammell, T. E. \& Lu, J. Hypothalamic regulation of sleep and circadian rhythms. Nature 437, 1257-1263 (2005).

29. Llinas, R. R. \& Steriade, M. Bursting of thalamic neurons and states of vigilance. J. Neurophysiol. 95, 3297-3308 (2006)

30. Tononi, G. Integrated information theory of consciousness: an updated account. Arch. Ital. Biol. 150, 293-329 (2012).

31. Dehaene, S. \& Changeux, J. P. Experimental and theoretical approaches to conscious processing. Neuron 70, 200-227 (2011)

32. Gusnard, D. A. \& Raichle, M. E. Searching for a baseline: functional imaging and the resting human brain. Nat. Rev. Neurosci. 2, 685-694 (2001).

33. Steriade, M. To burst, or rather, not to burst. Nat. Neurosci. 4, 671 (2001).

34. Grillner, S., Hellgren, J., Ménard, A., Saitoh, K. \& Wikström, M. A. Mechanisms for selection of basic motor programs - roles for the striatum and pallidum. Trends Neurosci. 28, 364-370 (2005).

35. Brown, E. N., Lydic, R. \& Schiff, N. D. General anesthesia, sleep, and coma. N. Engl. J. Med. 363, 2638-2650 (2010).

36. Casali, A. G. et al. A theoretically based index of consciousness independent of sensory processing and behavior. Sci. Transl. Med. 5, 198ra105 (2013).

37. Rosanova, M. et al. Recovery of cortical effective connectivity and recovery of consciousness in vegetative patients. Brain 135, 1308-1320 (2012).

38. Timofeev, I., Grenier, F., Bazhenov, M., Sejnowski, T. J. \& Steriade, M. Origin of slow cortical oscillations in deafferented cortical slabs. Cereb. Cortex 10, 1185-1199 (2000).

39. Steriade, M., Timofeev, I. \& Grenier, F. Natura waking and sleep states: a view from inside neocortical neurons. J. Neurophysiol. $\mathbf{8 5}$, 1969-1985 (2001).

40. Maxwell, W. L., MacKinnon, M. A., Smith, D. H., McIntosh, T. K. \& Graham, D. I. Thalamic nucle after human blunt head injury. J. Neuropathol. Exp. Neurol. 65, 478-488 (2006).

41. Schiff, N. D. Recovery of consciousness after brain injury: a mesocircuit hypothesis. Trends Neurosci. 33, 1-9 (2010).

42. Williams, S. T. et al. Common resting brain dynamics indicate a possible mechanism underlying zolpidem response in severe brain injury. Elife 2, pii: e01157 (2013).

43. Conte, M. M. et al. Longitudinal changes in the EEG spectrum during recovery after severe brain injury [abstract 659.8]. Presented at Neuroscience 2010

44. Baker, J. L. et al. Behavioral modulation with central thalamic deep brain stimulation in nonhuman primates [abstract 597.14]. Presented at Neuroscience 2012
45. Fridman, E. A., Beattie, B. J., Broft, A., Laureys, S. \& Schiff, N. D. Reversal of central thalamic and globus pallidus resting metabolic profiles: a marker of impaired anterior forebrain mesocircuit function [abstract 442.15]. Presented at Neuroscience 2013.

46. Schiff, N. D. et al. Behavioural improvements with thalamic stimulation after severe traumatic brain injury. Nature 448, 600-603 (2007).

47. Giacino, J. T. et al. Development of practice guidelines for assessment and management of the vegetative and minimally conscious states. J. Head Trauma Rehabil. 12, 79-89 (1997).

48. Schnakers, C. et al. Diagnostic accuracy of the vegetative and minimally conscious state: clinical consensus versus standardized neurobehavioral assessment. BMC Neurol. 9, 35 (2009).

49. Majerus, S., Gill-Thwaites, H., Andrews, K. $\&$ Laureys, S. Behavioral evaluation of consciousness in severe brain damage. Prog. Brain Res. 150, 397-413 (2005).

50. Seel, R. et al. Assessment scales for disorders of consciousness: evidence-based recommendations for clinical practice and research. Arch. Phys. Med. Rehabil. 91, 1-19 (2010).

51. Turgeon, A. F. et al. Mortality associated with withdrawal of life-sustaining therapy for patients with severe traumatic brain injury: a Canadian multicentre cohort study. CMAJ 183, 1581-1588 (2011).

52. Giacino, J. T. \& Smart, C. M. Recent advances in behavioral assessment of individuals with disorders of consciousness. Curr. Opin. Neurol. 20, 614-619 (2007)

53. Giacino, J. T., Hirsch, J., Schiff, N. \& Laureys, S. Functional neuroimaging applications for assessment and rehabilitation planning in patients with disorders of consciousness. Arch. Phys. Med. Rehabil. 87 (Suppl. 2), S67-S76 (2006)

54. Goldfine, A. M., Victor, J. D., Conte, M. M., Bardin, J. C. \& Schiff, N. D. Determination of awareness in patients with severe brain injury using EEG power spectral analysis. Clin. Neurophysiol. 122, 2157-2168 (2011).

55. Soddu, A. et al. Reaching across the abyss: recent advances in functional magnetic resonance imaging and their potential relevance to disorders of consciousness. Prog. Brain Res. 177, 261-274 (2009).

56. Giacino, J. T., Kalmar, K. \& Whyte, J. The JFK Coma Recovery Scale-Revised: measurement characteristics and diagnostic utility. Arch. Phys. Med. Rehabil. 85, 2020-2029 (2004).

57. Giacino, J. T. \& Whyte, J. The vegetative and minimally conscious states: current knowledge and remaining questions. J. Head Trauma Rehabil. 20, 30-50 (2005).

58. Giacino, J. T. \& Trott, C. T. Rehabilitative management of patients with disorders of consciousness: grand rounds. J. Head Trauma Rehabil. 19, 254-265 (2004)

59. Whyte, J. \& DiPasquale, M. C. Assessment of vision and visual attention in minimally responsive brain injured patients. Arch. Phys. Med. Rehabil. 76, 804-810 (1995).

60. Whyte, J., DiPasquale, M. C. \& Vaccaro, M. Assessment of command-following in minimally conscious brain injured patients. Arch. Phys. Med. Rehabil. 80, 653-660 (1999).

61. DiPasquale, M. C. \& Whyte, J. The use of quantitative data in treatment planning for minimally conscious patients. J. Head Trauma Rehabil. 11, 9-17 (1996).

62. Bodart, O. \& Laureys, S. in Oxford Textbook of Neurointensive Critical Care (eds Smith, M. et al., in press). 
63. Kampfl, A. et al. Prediction of recovery from posttraumatic vegetative state with cerebral magnetic-resonance imaging. Lancet 351, 1763-1767 (1998).

64. Galanaud, D. et al. Assessment of white matter injury and outcome in severe brain trauma: a prospective multicenter cohort. Anesthesiology 117, 1300-1310 (2012).

65. Luyt, C. E. et al. Diffusion tensor imaging to predict long-term outcome after cardiac arrest: a bicentric pilot study. Anesthesiology 117, 1311-1321 (2012).

66. Voss, H. U. et al. Possible axonal regrowth in late recovery from the minimally conscious state. J. Clin. Invest. 116, 2005-2011 (2006).

67. Laureys, S. et al. Impaired effective cortical connectivity in vegetative state. Neuroimage 9 , 377-382 (1999).

68. Laureys, S., Lemaire, C., Maquet, P., Phillips, C. $\&$ Franck, G. Cerebral metabolism during vegetative state and after recovery to consciousness. J. Neurol. Neurosurg. Psychiatry 67, 121 (1999).

69. Phillips, C. L. et al. "Relevance vector machine" consciousness classifier applied to cerebral metabolism of vegetative and locked-in patients. Neuroimage 56, 797-808 (2011).

70. Corrigan, J. D., Smith-Knapp, K. \& Granger, C. V. Validity of the functional independence measure for persons with traumatic brain injury. Arch. Phys. Med. Rehabil. 78, 828-834 (1997).

71. Vanhaudenhuyse, A. et al. Two distinct neuronal networks mediate the awareness of environment and of self. J. Cogn. Neurosci. 23, 570-578 (2011).

72. Bruno, M. A., Vanhaudenhuyse, A., Thibaut, A. Moonen, G. \& Laureys, S. From unresponsive wakefulness to minimally conscious PLUS and functional locked-in syndromes: recent advances in our understanding of disorders of consciousness. J. Neurol. 258, 1373-1384 (2011).

73. Gosseries, O. et al. Disorders of consciousness: what's in a name? NeuroRehabilitation 28, 3-14 (2011).

74. Bruno, M. A. et al. Functional neuroanatomy underlying the clinical subcategorization of minimally conscious state patients. J. Neurol. 259, 1087-1098 (2012).

75. Laureys, S. et al. Cortical processing of noxious somatosensory stimuli in the persistent vegetative state. Neuroimage 17, 732-741 (2002).

76. Laureys, S. et al. Auditory processing in the vegetative state. Brain 123, 1589-1601 (2000).

77. Boly, M. et al. Auditory processing in severely brain injured patients: differences between the minimally conscious state and the persistent vegetative state. Arch. Neurol. 61, 233-238 (2004).

78. Laureys, S. et al. Cerebral processing in the minimally conscious state. Neurology 63, 916-918 (2004).

79. Boly, M. et al. Perception of pain in the minimally conscious state with PET activation: an observational study. Lancet Neurol. 7, 1013-1020 (2008)

80. Di, H., Boly, M., Weng, X., Ledoux, D. \& Laureys, S. Neuroimaging activation studies in the vegetative state: predictors of recovery? Clin. Med. 8, 502-507 (2008).

81. Edlow, B. L., Giacino, J. T. \& Wu, O. Functional $\mathrm{MRI}$ and outcome in traumatic coma. Curr. Neurol. Neurosci. Rep. 13, 375 (2013).

82. Huang, Z. et al. The self and its resting state in consciousness: an investigation of the vegetative state. Hum. Brain Mapp. http:// dx.doi.org/10.1002/hbm.22308.
83. Laureys, S. Death, unconsciousness and the brain. Nat. Rev. Neurosci. 6, 899-909 (2005).

84. Boly, M. et al. When thoughts become action: an fMRI paradigm to study volitional brain activity in non-communicative brain injured patients. Neuroimage 36, 979-992 (2007).

85. Monti, M. M. et al. Willful modulation of brain activity in disorders of consciousness. N. Engl. J. Med. 362, 579-589 (2010).

86. Owen, A. M. et al. Detecting awareness in the vegetative state. Science 313, 1402 (2006).

87. Bekinschtein, T. A., Manes, F. F., Villarreal, M. Owen, A. M. \& Della-Maggiore, V. Functional imaging reveals movement preparatory activity in the vegetative state. Front. Hum. Neurosci. 5, 5 (2011).

88. Bardin, J. C. et al. Dissociations between behavioural and functional magnetic resonance imaging-based evaluations of cognitive function after brain injury. Brain 134, 769-782 (2011).

89. Monti, M. M., Pickard, J. D. \& Owen, A. M. Visual cognition in disorders of consciousness: from V1 to top-down attention. Hum. Brain Mapp. 34, 1245-1253 (2013).

90. Majerus, S., Bruno, M. A., Schnakers, C., Giacino, J. T. \& Laureys, S. The problem of aphasia in the assessment of consciousness in brain-damaged patients. Prog. Brain Res. 177, 49-61 (2009).

91. Heine, L. et al. Resting state networks and consciousness: alterations of multiple resting state network connectivity in physiological, pharmacological, and pathological consciousness States. Front. Psychol. 3, 295 (2012).

92. Guldenmund, P., Vanhaudenhuyse, A., Boly, M., Laureys, S. \& Soddu, A. A default mode of brain function in altered states of consciousness. Arch. Ital. Biol. 150, 107-121 (2012).

93. Demertzi, A., Soddu, A. \& Laureys, S. Consciousness supporting networks. Curr. Opin. Neurobiol. 23, 239-244 (2013).

94. Boly, M. et al. Consciousness and cerebral baseline activity fluctuations. Hum. Brain Mapp. 29, 868-874 (2008).

95. Demertzi, A. et al. Looking for the self in pathological unconsciousness. Front. Hum. Neurosci. 7, 538 (2013).

96. Boly, M. et al. Functional connectivity in the default network during resting state is preserved in a vegetative but not in a brain dead patient. Hum. Brain Mapp. 30, 2393-2400 (2009).

97. Vanhaudenhuyse, A. et al. Default network connectivity reflects the level of consciousness in non-communicative brain-damaged patients. Brain 133, 161-171 (2010).

98. Cauda, F. et al. Disrupted intrinsic functional connectivity in the vegetative state. J. Neurol. Neurosurg. Psychiatry 80, 429-431 (2009).

99. Soddu, A. et al. Identifying the default-mode component in spatial IC analyses of patients with disorders of consciousness. Hum. Brain Mapp. 33, 778-796 (2012).

100. Ovadia-Caro, S. et al. Reduction in interhemispheric connectivity in disorders of consciousness. PLoS ONE 7, e37238 (2012).

101. Liu, A. A., Voss, H. U., Dyke, J. P., Heier, L. A. \& Schiff, N. D. Arterial spin labeling and altered cerebral blood flow patterns in the minimally conscious state. Neurology 77, 1518-1523 (2011).

102. Ricci, R. et al. Localised proton MR spectroscopy of brain metabolism changes in vegetative patients. Neuroradiology 39, 313-319 (1997).

103. Uzan, M. et al. Thalamic proton magnetic resonance spectroscopy in vegetative state induced by traumatic brain injury. J. Neurol. Neurosurg. Psychiatry 74, 33-38 (2003).
104. Tollard, E. et al. Experience of diffusion tensor imaging and $1 \mathrm{H}$ spectroscopy for outcome prediction in severe traumatic brain injury: preliminary results. Crit. Care Med. 37 , 1448-1455 (2009).

105. Carpentier, A. et al. Early morphologic and spectroscopic magnetic resonance in severe traumatic brain injuries can detect "invisible brain stem damage" and predict "vegetative states". J. Neurotrauma 23, 674-685 (2006).

106. Lehembre, R. et al. Electrophysiological investigations of brain function in coma, vegetative and minimally conscious patients. Arch. Ital. Biol. 150, 122-139 (2012).

107. Vanhaudenhuyse, A., Laureys, S. \& Perrin, F. Cognitive event-related potentials in comatose and post-comatose states. Neurocrit. Care $\mathbf{8}$, 262-270 (2008).

108. Bruno, M. A., Gosseries, O., Ledoux, D., Hustinx, R. \& Laureys, S. Assessment of consciousness with electrophysiological and neurological imaging techniques. Curr. Opin. Crit. Care 17, 146-151 (2011).

109. Sandroni, C. et al. Predictors of poor neurological outcome in adult comatose survivors of cardiac arrest: a systematic review and meta-analysis.

Part 2: Patients treated with therapeutic hypothermia. Resuscitation 84, 1324-1338 (2013).

110. Kobylarz, E. J. \& Schiff, N. D. Neurophysiological correlates of persistent vegetative and minimally conscious states. Neuropsychol. Rehabil. 15, 323-332 (2005).

111. Lehembre, R. et al. Resting-state EEG study of comatose patients: a connectivity and frequency analysis to find differences between vegetative and minimally conscious states. Funct. Neurol. 27, 41-47 (2012).

112. Gosseries, O. et al. Automated EEG entropy measurements in coma, vegetative state/ unresponsive wakefulness syndrome and minimally conscious state. Funct. Neurol. 26, 25-30 (2011).

113. Schnakers, C. et al. Diagnostic and prognostic use of bispectral index in coma, vegetative state and related disorders. Brain Inj. 22, 926-931 (2008).

114. Schnakers, C., Majerus, S. \& Laureys, S. Bispectral analysis of electroencephalogram signals during recovery from coma: preliminary findings. Neuropsychol. Rehabil. 15, 381-388 (2005).

115. Cologan, V. et al. Sleep in disorders of consciousness. Sleep Med. Rev. 14, 97-105 (2010).

116. Cologan, V. et al. Sleep in the unresponsive wakefulness syndrome and minimally conscious state. J. Neurotrauma 30, 339-346 (2013).

117. Landsness, E. et al. Electrophysiological correlates of behavioural changes in vigilance in vegetative state and minimally conscious state. Brain 134, 2222-2232 (2011).

118. Estraneo, A. et al. Predictors of recovery of responsiveness in prolonged anoxic vegetative state. Neurology 80, 464-470 (2013).

119. Wijdicks, E. F., Hijdra, A., Young, G. B., Bassetti, C. L. \& Wiebe, S. Practice parameter: prediction of outcome in comatose survivors after cardiopulmonary resuscitation (an evidencebased review): report of the Quality Standards Subcommittee of the American Academy of Neurology. Neurology 67, 203-210 (2006).

120. Tzovara, A. et al. Progression of auditory discrimination based on neural decoding predicts awakening from coma. Brain 136, 81-89 (2013)

121. Qin, P. et al. Mismatch negativity to the patient's own name in chronic disorders of consciousness. Neurosci. Lett. 448, 24-28 (2008). 
122. Perrin, F. et al. Brain response to one's own name in vegetative state, minimally conscious state, and locked-in syndrome. Arch. Neurol. 63, 562-569 (2006).

123. Bekinschtein, T. A. et al. Neural signature of the conscious processing of auditory regularities. Proc. Natl Acad. Sci. USA 106, 1672-1677 (2009).

124. King, J. R. et al. Single-trial decoding of auditory novelty responses facilitates the detection of residual consciousness. Neuroimage $83 \mathrm{C}$, 726-738 (2013).

125. Boly, M. et al. Preserved feedforward but impaired top-down processes in the vegetative state. Science 332, 858-862 (2011).

126. Schnakers, C. et al. Voluntary brain processing in disorders of consciousness. Neurology 71 , 1614-1620 (2008).

127. Schnakers, C. et al. Detecting consciousness in a total locked-in syndrome: an active eventrelated paradigm. Neurocase $15,271-277$ (2009).

128. Kotchoubey, B., Lang, S., Winter, S. \& Birbaumer, N. Cognitive processing in completely paralyzed patients with amyotrophic lateral sclerosis. Eur. J. Neurol. 10, 551-558 (2003).

129. Coronado, V. G., McGuire, L. M., Faul M., Sugerman, D. E. \& Pearson, W. S. Traumatic brain injury epidemiology and public health issues. In Brain Injury Medicine: Principles and Practice $2^{\text {nd }}$ edn (eds Zasler, N. D. et al.) 84-100 (Demos Medical, 2012).

130. Cruse, D. et al. Bedside detection of awareness in the vegetative state: a cohort study. Lancet 378, 2088-2094 (2011).

131. Goldfine, A. M. et al. Reanalysis of "Bedside detection of awareness in the vegetative state: a cohort study". Lancet 381, 289-291 (2013).

132. Chatelle, C. et al. Brain-computer interfacing in disorders of consciousness. Brain Inj. 26, 1510-1522 (2012).

133. Lule, D. et al. Probing command following in patients with disorders of consciousness using a brain-computer interface. Clin. Neurophysiol. 124, 101-106 (2013).

134. Bekinschtein, T. A., Coleman, M. R., Niklison, J. $3^{\text {rd }}$, Pickard, J. D. \& Manes, F. F. Can electromyography objectively detect voluntary movement in disorders of consciousness? J. Neurol. Neurosurg. Psychiatry 79, 826-828 (2007).

135. Stoll, J. et al. Pupil responses allow communication in locked-in syndrome patients. Curr. Biol. 23, R647-R648 (2013).

136. Wilhelm, B., Jordan, M. \& Birbaumer, N. Communication in locked-in syndrome: effects of imagery on salivary $\mathrm{pH}$. Neurology $67,534-535$ (2006).

137. Lapitskaya, N. et al. Abnormal corticospinal excitability in patients with disorders of consciousness. Brain Stimul. 6, 590-597 (2013).

138. Boly, M. et al. Brain connectivity in disorders of consciousness. Brain Connect. 2, 1-10 (2012).

139. Nakase-Richardson, R. et al. Do rehospitalization rates differ among injury severity levels in the NIDRR Traumatic Brain Injury Model Systems program? Arch. Phys. Med. Rehabil. 94 1884-1890 (2013).

140. Whyte, J. et al. Medical complications during inpatient rehabilitation among patients with traumatic disorders of consciousness. Arch. Phys. Med. Rehabil. 94, 1877-1883 (2013).

141. Giacino, J. T. \& Zasler, N. D. Outcome after severe traumatic brain injury: coma, the vegetative state, and the minimally responsive state. J. Head Trauma Rehabil. 10, 40-56 (1995).

142. Andrews, K. International Working Party on the Management of the Vegetative State: summary report. Brain Inj. 10, 797-806 (1996).

143. Giacino, J. in Rehabilitation for Traumatic Brain Injury (eds High, W. et al.) 305-337 (Oxford University Press, 2005).

144. Leong, B. The vegetative and minimally conscious states in children: spasticity, muscle contracture and issues for physiotherapy treatment. Brain Inj. 16, 217-230 (2002).

145. Boly, M. et al. Cerebral processing of auditory and noxious stimuli in severely brain injured patients: differences between VS and MCS. Neuropsychol. Rehabil. 15, 283-289 (2005).

146. Schnakers, C. \& Zasler, N. D. Pain assessment and management in disorders of consciousness. Curr. Opin. Neurol. 20, 620-626 (2007).

147. Schnakers, C., Faymonville, M.-E. \& Laureys, S. Ethical implications: pain, coma, and related disorders. Encyclopedia of Consciousness 1, 243-250 (2009).

148. Faugeras, F. et al. Probing consciousness with event-related potentials in the vegetative state. Neurology 77, 264-268 (2011).

149. Whyte, J. Treatments to enhance recovery from the vegetative and minimally conscious states: ethical issues surrounding efficacy studies. Am. J. Phys. Med. Rehabil. 86, 86-92 (2007).

150. Hagan, C., Malkmus, D. \& Durham, P. in Rehabilitation of the Head-Injured Adult: Comprehensive Physical Management (Professional Staff Association of Rancho Los Amigos Hospital Inc., 1979).

151. Mackay, L. E., Bernstein, B. A., Chapman, P. E., Morgan, A. S. \& Milazzo, L. S. Early intervention in severe head injury: long-term benefits of a formalized program. Arch. Phys. Med. Rehabil. 73, 635-641 (1992).

152. Rappaport, M., Hall, K. M., Hopkins, K., Belleza, T. \& Cope, D. N. Disability rating scale for severe head trauma: coma to community. Arch. Phys. Med. Rehabil. 63, 118-123 (1982).

153. Clauss, R. \& Nel, W. Drug induced arousal from the permanent vegetative state. NeuroRehabilitation 21, 23-28 (2006).

154. Shames, J. L. \& Ring, H. Transient reversal of anoxic brain injury-related minimally conscious state after zolpidem administration: a case report. Arch. Phys. Med. Rehabil. 89, 386-388 (2008).

155. Brefel-Courbon, C. et al. Clinical and imaging evidence of zolpidem effect in hypoxic encephalopathy. Ann. Neurol. 62, 102-105 (2007).

156. Cohen, S. I. \& Duong, T. T. Increased arousal in a patient with anoxic brain injury after administration of zolpidem. Am. J. Phys. Med. Rehabil. 87, 229-231 (2008).

157. Whyte, J. \& Myers, R. Incidence of clinically significant responses to zolpidem among patients with disorders of consciousness: a preliminary placebo controlled trial. Am. J. Phys. Med. Rehabil. 88, 410-418 (2009).

158. Singh, R. et al. Zolpidem in a minimally conscious state. Brain Inj. 22, 103-106 (2008).

159. Sara, M., Pistoia, F., Mura, E., Onorati, P. \& Govoni, S. Intrathecal baclofen in patients with persistent vegetative state: 2 hypotheses. Arch. Phys. Med. Rehabil. 90, 1245-1249 (2009).

160. Taira, T. Intrathecal administration of GABA agonists in the vegetative state. Prog. Brain Res. 177, 317-328 (2009).

161. Thonnard, M. et al. Effect of zolpidem in chronic disorders of consciousness: a prospective openlabel study. Funct. Neurol. (in press).
162. Giacino, J., Fins, J. J., Machado, A. \& Schiff, N. D. Central thalamic deep brain stimulation to promote recovery from chronic posttraumatic minimally conscious state: challenges and opportunities. Neuromodulation 15, 339-349 (2012).

163. Lombardi, F., Taricco, M., De Tanti, A., Telaro, E. \& Liberati, A. Sensory stimulation for brain injured individuals in coma or vegetative state. Cochrane Database of Systematic Reviews, Issue 2. Art. No.:CD001427. http://dx.doi.org/ 10.1002/14651858.CD001427.

164. Pistoia, F., Sacco, S., Carolei, A. \& Sara, M. Corticomotor facilitation in vegetative state: results of a pilot study. Arch. Phys. Med. Rehabil. 94, 1599-1606 (2013).

165. Rockswold, G. L., Ford, S. E., Anderson, D. C., Bergman, T. A. \& Sherman, R. E. Results of a prospective randomized trial for treatment of severely brain-injured patients with hyperbaric oxygen. J. Neurosurg. 76, 929-934 (1992).

166. Warden, D. L. et al. Guidelines for the pharmacologic treatment of neurobehavioral sequelae of traumatic brain injury. J. Neurotrauma 23, 1468-1501 (2006).

167. Fins, J. J. Disorders of consciousness and disordered care: families, caregivers, and narratives of necessity. Arch. Phys. Med. Rehabil. 94, 1934-1939 (2013).

168. Matter of Karen Quinlan, 70 N.J. 10, 355 A.2d 677 (1976).

169. Fins, J. J. Affirming the right to care, preserving the right to die: disorders of consciousness and neuroethics after Schiavo. Palliat. Support. Care 4, 169-178 (2006).

170. Fins, J. J., Schiff, N. D. \& Foley, K. M. Late recovery from the minimally conscious state ethical and policy implications. Neurology 68 , 304-307 (2007)

171. Fins, J. J. \& Hersh, J. in Patients as Policy Actors (eds Hoffman, B. et al.) 21-42 (Rutgers University Press, 2011).

172. Fins, J. J. Ethics of clinical decision making and communication with surrogates. In Plum and Posner's Diagnosis of Stupor and Coma, $4^{\text {th }}$ edn 376-386 (Oxford University Press, 2007).

173. Wijdicks, E. F. \& Rabinstein, A. A. The family conference: end-of-life guidelines at work for comatose patients. Neurology 68, 1092-1094 (2007).

174. Fins, J. \& Pohl, B. in Oxford Textbook of Palliative Medicine (eds Hanks, G. et al.) (Oxford University Press, in press).

175. Fins, J. J. Severe brain injury and organ solicitation: a call for temperance. Virtual Mentor 14, 221-226 (2012)

176. Fins, J. J., Master, M. G., Gerber, L. M. \& Giacino, J. T. The minimally conscious state: a diagnosis in search of an epidemiology. Arch. Neurol. 64, 1400-1405 (2007).

177. Schiff, N. D. \& Fins, J. J. Hope for “comatose" patients. Cerebrum 5, 7-24 (2003).

178. Lammi, M. H., Smith, V. H., Tate, R. L. \& Taylor, C. M. The minimally conscious state and recovery potential: a follow-up study 2 to 5 years after traumatic brain injury. Arch. Phys. Med. Rehabil. 86, 746-754 (2005).

179. Whyte, J. \& Nakase-Richardson, R. Disorders of consciousness: outcomes, comorbidities and care needs. Arch. Phys. Med. Rehabil. 94, 1851-1854 (2013).

180. InterQual Evidence-based Clinical Content. McKesson [online], http://www.mckesson.com/ payers/decision-management/ interqual-evidence-based-clinical-content/ interqual-evidence-based-clinical-content/ (2013).

181. Canedo, A., Grix, M. C. \& Nicoletti, J. An analysis of assessment instruments for the minimally 
responsive patient (MRP): clinical observations. Brain Inj. 16, 453-461 (2002).

182. Berube, J. et al. The Mohonk Report: a report to Congress. Disorders of consciousness: assessment, treatment, and research needs. Northeast Center for Rehabilitation and Brain Injury [online], http://www.northeastcenter. com/the-mohonk-report-disorders-of-consciousn ess-assessment-treatment-research-needs.pdf (2006).

183. Fins, J. J. Wait, wait...don't tell me: tuning in the injured brain. Arch. Neurol. 69, 158-160 (2012).

184. Fins, J. J. The ethics of measuring and modulating consciousness: the imperative of minding time. Prog. Brain Res. 177, 371-382 (2009).

185. McNamee, S., Howe, L., Nakase-Richardson, R. \& Peterson, M. Treatment of disorders of consciousness in the Veterans Health Administration polytrauma centers. J. Head Trauma Rehabil. 27, 244-252 (2012).

186. Fins, J. J. A proposed ethical framework for interventional cognitive neuroscience: a consideration of deep brain stimulation in impaired consciousness. Neurol. Res. 22, 273-278 (2000).

187. Miller, F. G. \& Fins, J. J. Protecting vulnerable research subjects without unduly constraining neuropsychiatric research. Arch. Gen. Psychiatry 56, 701-702 (1999).

188. Fins, J. \& Miller, F. Enrolling decisionally incapacitated subjects in neuropsychiatric research. CNS Spectr. 5, 32-40 (2000).

189. Fins, J. J. Justice, clinical research and the minimally conscious state. Presidential Commission for the Study of Bioethical Issues [online], http://www.tvworldwide.com/events/ bioethics/110519/ (2011).

190. O'Sullivan, J. L. Role of the attorney for the alleged incapacitated person. Stetson L. Rev. 31, 687-734 (2001).

191. Conference of State Court Administrators. The Demographic Imperative: Guardianships and Conservatorships. (COSCA White Paper, adopted 2010).
192. Anderson, T. P. \& Fearey, M. S. Legal guardianship in traumatic brain injury rehabilitation: ethical implications. J. Head Trauma Rehabil. 4, 57-64 (1989).

193. Teaster, P. B., Schmidt, W. C. Jr, Lawrence, S. A. Mendiondo, M. S. \& American Bar Association. Public Guardianship: In the Best Interest of Incapacitated People? (Praeger, 2010).

194. Fins, J. J. Minds apart: severe brain injury, citizenship, and civil rights. Law and Neuroscience: Current Legal Issues 13, 367-384 (2010).

195. Owen, A. M., Schiff, N. D. \& Laureys, S. A new era of coma and consciousness science. Prog. Brain Res. 177, 399-411 (2009).

196. Di Perri, C. et al. Limbic hyperconnectivity in the vegetative state. Neurology 81, 1417-1424 (2013).

197. Fins, J. J. et al. Neuroimaging and disorders of consciousness: envisioning an ethical research agenda. Am. J. Bioeth. 8, 3-12 (2008).

198. Voss, H. U., Heier, L. A. \& Schiff, N. D. Multimodal imaging of recovery of functional networks associated with reversal of paradoxical herniation after cranioplasty. Clin. Imaging 35 , 253-258 (2011).

199. Bruno, M. A. et al. Multimodal neuroimaging in patients with disorders of consciousness showing "functional hemispherectomy". Prog. Brain Res. 193, 323-333 (2011).

200. Tshibanda, L. et al. Neuroimaging after coma. Neuroradiology 52, 15-24 (2010).

201. Tshibanda, L. et al. Magnetic resonance spectroscopy and diffusion tensor imaging in coma survivors: promises and pitfalls. Prog. Brain Res. 177, 215-229 (2009).

202. Bruno, M. A. et al. Visual fixation in the vegetative state: an observational case series PET study. BMC Neurol. 10, 35 (2010).

203. Jox, R. J., Bernat, J. L., Laureys, S. \& Racine, E. Disorders of consciousness: responding to requests for novel diagnostic and therapeutic interventions. Lancet Neurol. 11, 732-738 (2012).
204. Gill-Thwaites, H. \& Munday, R. The Sensory Modality Assessment Rehabilitation Technique (SMART): a valid and reliable assessment for the vegetative and minimally conscious state patient. Brain Inj. 18, 1255-1269 (2004).

205. Ansell, B. J. \& Keenan, J. E. The Western Neuro Sensory Stimulation Profile: a tool for assessing slow-to-recover head-injured patients. Arch. Phys. Med. Rehabil. 70, 104-108 (1989).

206. Rader, M. A., Alston, J. \& Ellis, D. W. Sensory stimulation of severely brain-injured patients. Brain Inj. 3, 141-147 (1989).

207. Shiel, A. et al. The Wessex Head Injury Matrix (WHIM) main scale: a preliminary report on a scale to assess and monitor patient recovery after severe head injury. Clin Rehabil. 14, 408-416 (2000)

208. Pape, T. L., Heinemann, A. W., Kelly, J. P., Hurder, A. G. \& Lundgren, S. A measure of neurobehavioral functioning after coma. Part I: Theory, reliability, and validity of the Disorders of Consciousness Scale. J. Rehabil. Res. Dev. 42, 1-17 (2005).

209. American Academy of Neurology Guideline Process Manual. AAN.com [online], https:// www.aan.com/Guidelines/Home/Development (2011).

\section{Acknowledgements}

This work was supported by the National Institute on Disability and Rehabilitation Research Traumatic Brain Injury Model Systems (H133A120085), James S. McDonnell Foundation, Belgian Funds for Scientific Research (FRS), European Commission,

European Space Agency, Wallonia-Brussels Federation Concerted Research Action, Mind Science Foundation and Belgian InterUniversity Attraction Pole.

\section{Author contributions}

All four authors researched data for the article, made substantial contributions to discussions of the content, wrote the article, and reviewed and/or edited the manuscript before submission. 